\title{
The Effects of Chronic Stress and Exercise on Mouse Pancreatic Islet of Langerhans Morphology and Muscle Atrophy Gene Expression
}

Travis Parkulo

West Virginia University

Follow this and additional works at: https://researchrepository.wvu.edu/etd

\section{Recommended Citation}

Parkulo, Travis, "The Effects of Chronic Stress and Exercise on Mouse Pancreatic Islet of Langerhans Morphology and Muscle Atrophy Gene Expression" (2014). Graduate Theses, Dissertations, and Problem Reports. 265.

https://researchrepository.wvu.edu/etd/265

This Thesis is protected by copyright and/or related rights. It has been brought to you by the The Research Repository @ WVU with permission from the rights-holder(s). You are free to use this Thesis in any way that is permitted by the copyright and related rights legislation that applies to your use. For other uses you must obtain permission from the rights-holder(s) directly, unless additional rights are indicated by a Creative Commons license in the record and/ or on the work itself. This Thesis has been accepted for inclusion in WVU Graduate Theses, Dissertations, and Problem Reports collection by an authorized administrator of The Research Repository @ WVU. For more information, please contact researchrepository@mail.wvu.edu. 


\title{
The Effects of Chronic Stress and Exercise on Mouse Pancreatic Islet of Langerhans Morphology and Muscle Atrophy Gene Expression
}

\author{
Travis Parkulo, B.S.
}

Thesis submitted to the School of Medicine, Division of Exercise Physiology at West Virginia University in partial fulfillment of the requirements for the degree of Master of Science in Exercise Physiology

Committee:

\author{
Randall W. Bryner, Ed.D., Chair \\ Emidio Pistilli, Ph.D. \\ Stephen E. Alway, Ph.D.
}

Division of Exercise Physiology

Morgantown, West Virginia

2014

Keywords: Beta cell, Islet of Langerhans, chronic stress, muscle atrophy gene exercise

Copyright 2014 Travis Parkulo 


\title{
ABSTRACT \\ The Effects of Chronic Stress and Exercise on Mouse Pancreatic Islet of Langerhans Morphology and Muscle Atrophy Gene Expression
}

\author{
Travis Parkulo
}

Chronic stress has been implicated as a possible contributing factor to the onset of Type 2 Diabetes Mellitus through its negative effects on peripheral insulin sensitivity and the insulin producing $\beta$ cells of the pancreas. Exercise could serve as a possible countermeasure to the damaging effects of chronic stress due to its proven ability to increase insulin sensitivity at the level of the muscle and improve or maintain $\beta$ cell function and mass. To date, no published research has examined the effects of chronic stress in combination with voluntary wheel running on murine islet morphology and skeletal muscle atrophy. The purpose of this study was to evaluate the effects of chronic stress and voluntary wheel running on murine beta cell number per Islet, insulin positive area in the pancreas, hind limb skeletal muscle morphometrics, autophagy protein expression, and muscle atrophy gene expression. 40 Male Balb/c mice were randomized into 4 groups; sedentary ( $N=10$ : Sed), sedentary stressed ( $N=10$ : SedSt), exercise $(\mathrm{N}=10$ : $\mathrm{EX})$, and exercise stressed ( $\mathrm{N}=10$ : $\mathrm{EXSt}) .20$ mice were given free access to running wheels over 4 weeks after which, 10 were randomized to $7 \mathrm{hrs} / \mathrm{d}, 5 \mathrm{~d} / \mathrm{wk}$. of stress for 8 wks. 20 mice remained sedentary with no access to running wheels; after 4 weeks 10 of these mice were randomized to $7 \mathrm{hrs} / \mathrm{d}, 5 \mathrm{~d} / \mathrm{wk}$. of stress for 8 wks. The average islet area was significantly increased in ExSt $(24223.810 \pm 2670)$ when compared to Ex mice $(16811.00 \pm 2704)(P<.05)$. Average $\beta$ cell number per islet was significantly higher in ExSt (93.21 \pm 5.69$)$ and SedSt $(90.99 \pm 5.22)$ mice when compared to Ex $(68.64 \pm 3.73)$ or Sed $(70.73 \pm 4.77)(P<.05)$. Muscle wet weight was increased in EXSt mice vs. SedSt mice $(P<.05)$. These results indicate that 8 
weeks of chronic stress caused $\beta$ cell proliferation and an increase in islet area, but did not result in an increase in muscle ubiquitin associated atrophy gene mRNA levels. Exercise coupled with stress appeared to improve muscle protein accumulation and therefore, could be a potential means to reduce muscle losses under conditions of high stress or $\beta$ cell dysfunction. 

ABREVIATIONS
T2DM Type 2 Diabetes Mellitus
HPA Hypothalamic Pituitary Adrenal Axis
GC Glucocorticoid
IR Insulin Receptor
IRS-1 Insulin Receptor Substrate 1
MuRF-1 Muscle Ring Finger 1
MAFbx Muscle Atrophy F-box
CMS Chronic Mild Stress
CRF Corticotrophin Releasing Factor
CRH Corticotrophin Releasing Hormone
AVP Arginine-Vasopressin
ACTH Adrenocorticotropic Hormone
GR Glucocorticoid Receptor
PVN Paraventricular Nucleus
PFC Prefrontal Cortex
UPS Ubiquitin Proteolysis System
GSIS Glucose Stimulated Insulin Secretion
ZDF Zucker Diabetic Fatty 


\section{TABLE OF CONTENTS}

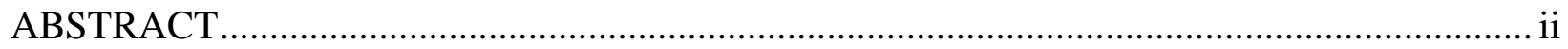

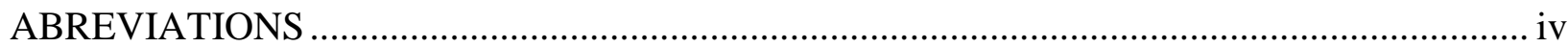

TABLE OF CONTENTS ............................................................................................... v

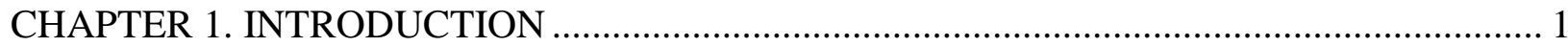

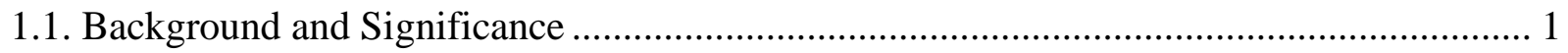

1.2. Purpose and Specific Aims ....................................................................................... 4

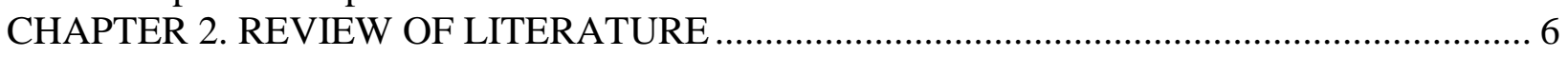

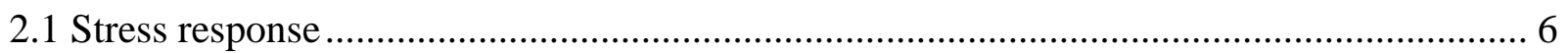

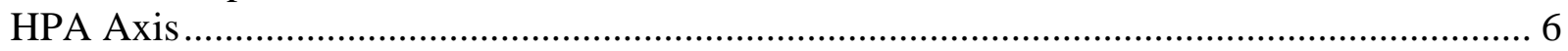

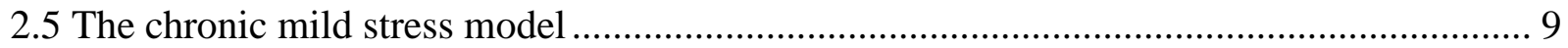

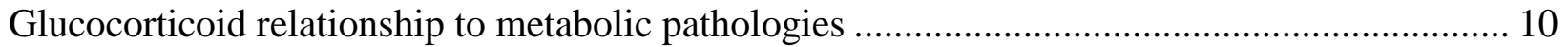

Direct Effect of GCs on Muscle ................................................................................. 11

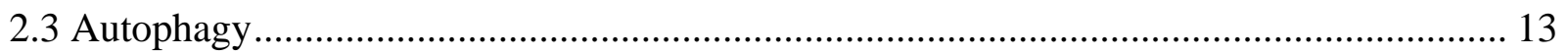

2.4 Direct and indirect effects of GCs on Islet morphology and function................................ 15

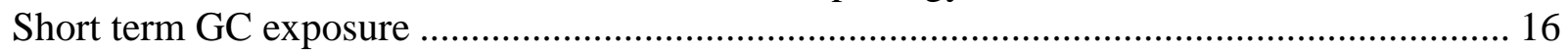

Prolonged and Intermittent GC exposure to $\beta$ cells .......................................................... 17

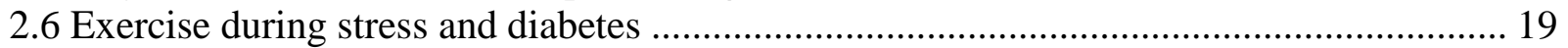

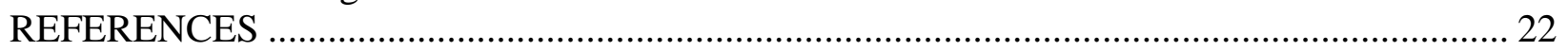

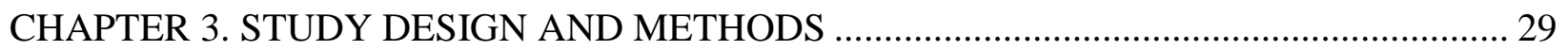

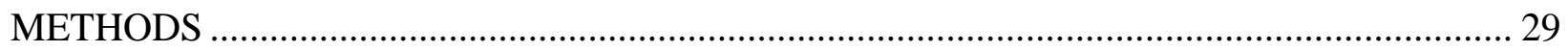

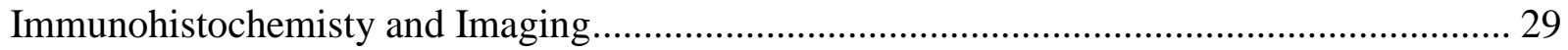

Islet morphology and Beta Cell counting ....................................................................... 30

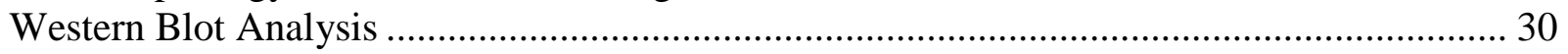

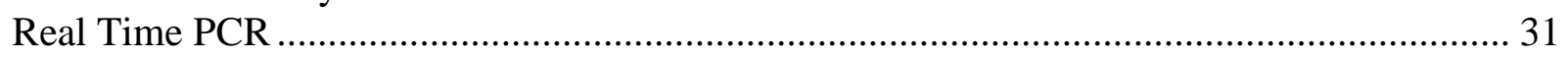

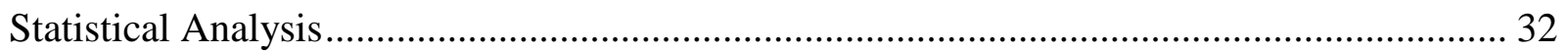

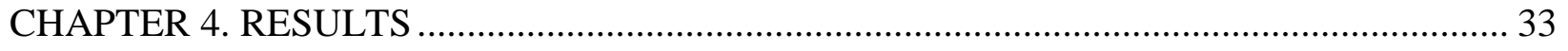

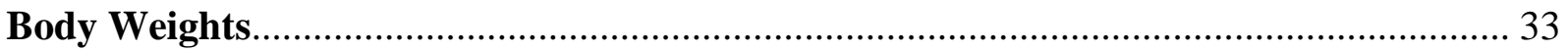

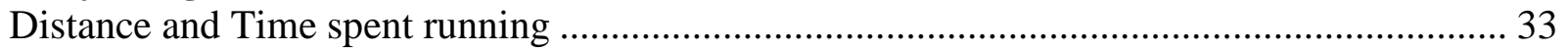

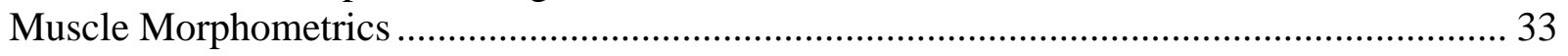

Mean $\beta$ cell number per islet........................................................................................... 34

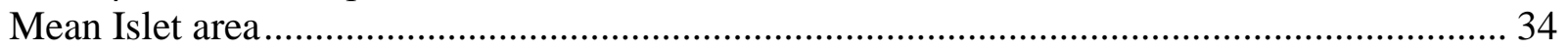

Muscle Specific atrophy gene expression........................................................................... 35

Ubiquitin Proteolysis gene expression............................................................................... 35

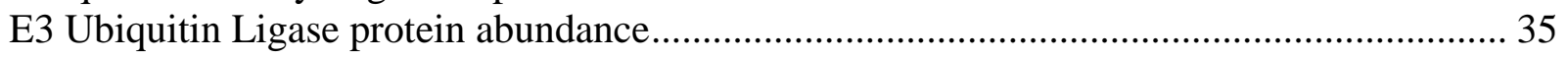

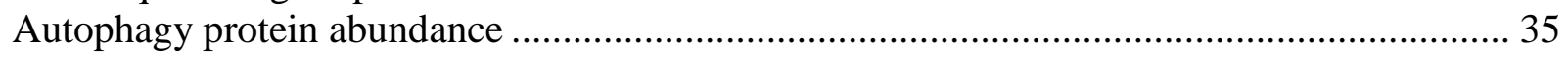

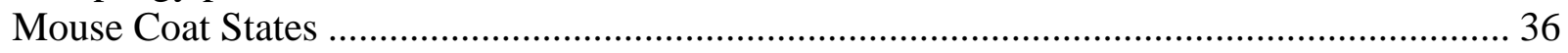

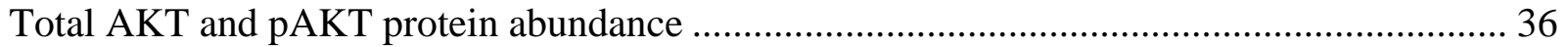

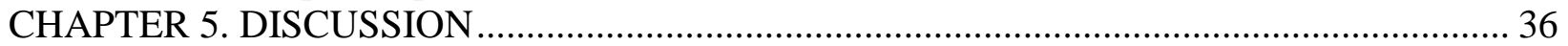

Limitations and Future Directives ........................................................................................... 43

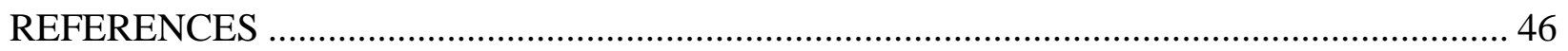

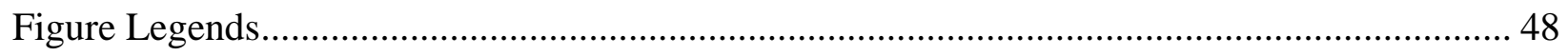

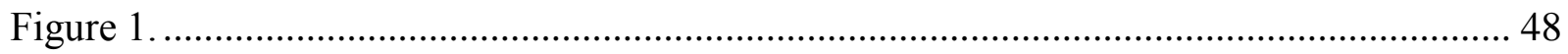

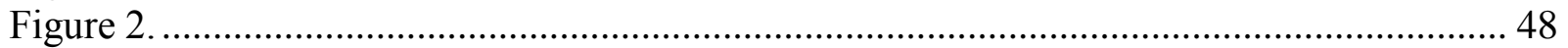




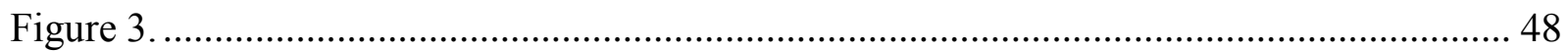

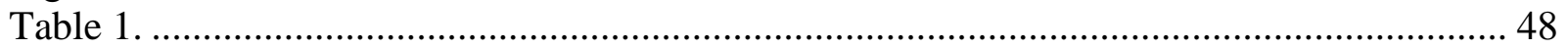

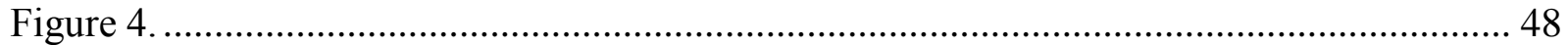

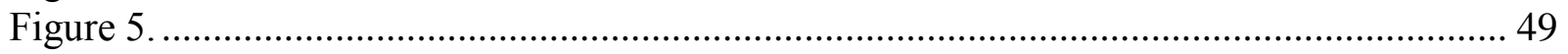

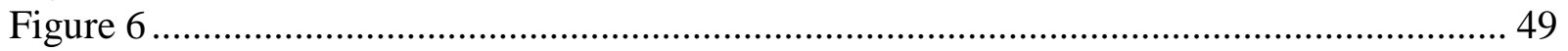

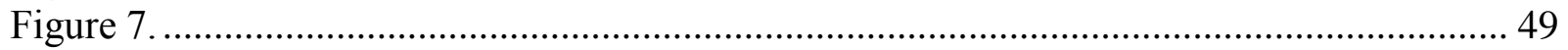

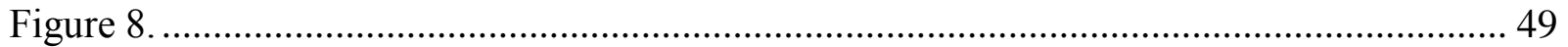

Figure 9

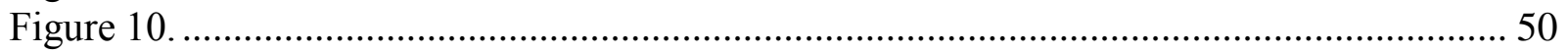

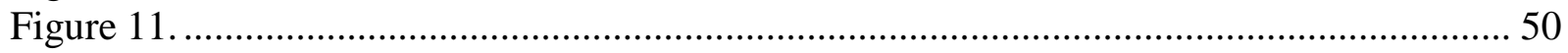

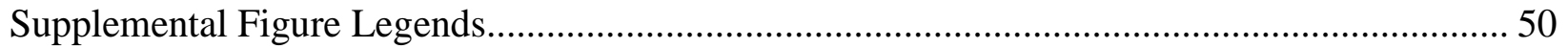

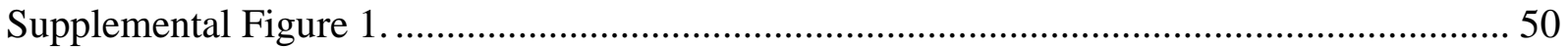

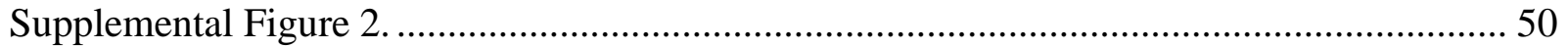

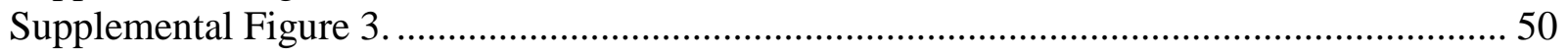

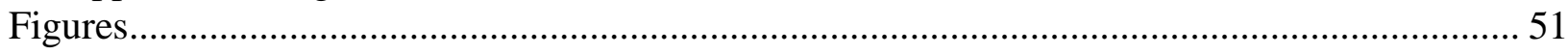

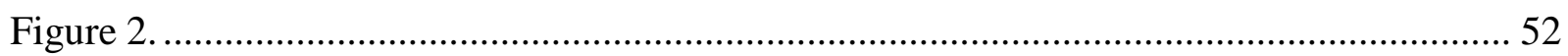

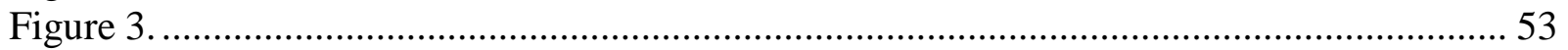

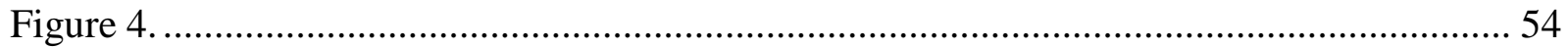

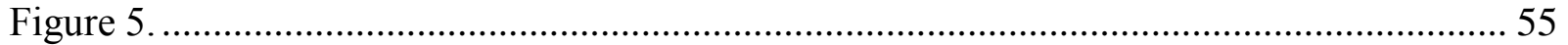

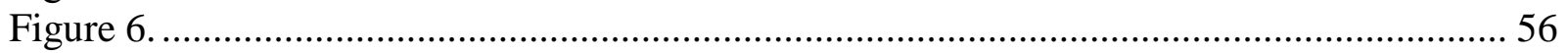

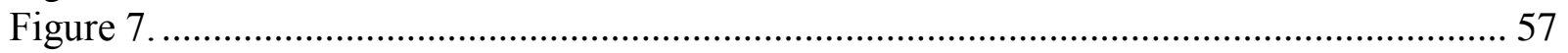

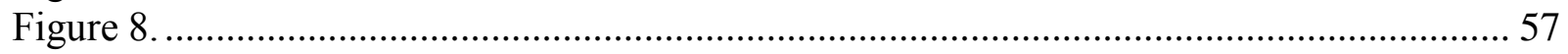

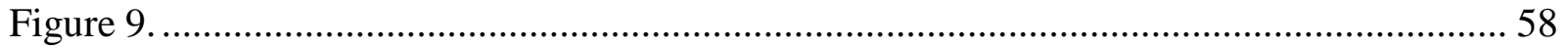

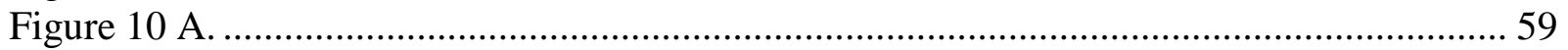

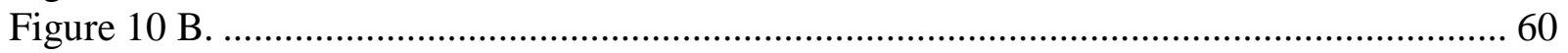

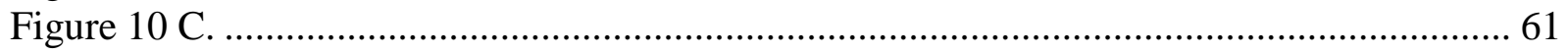

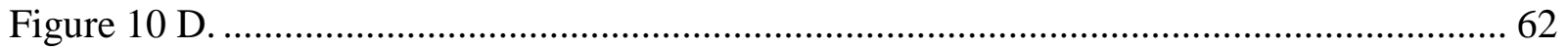

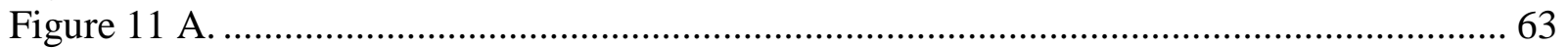

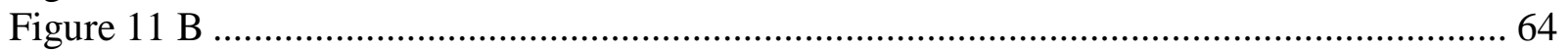

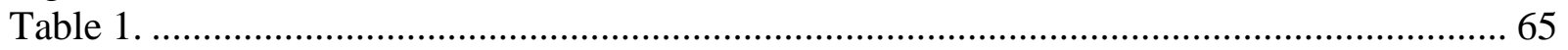

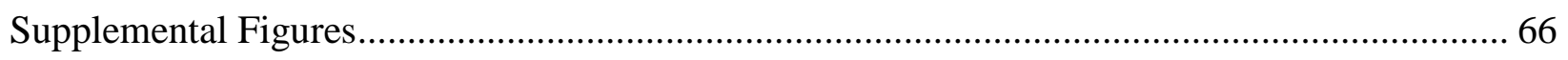

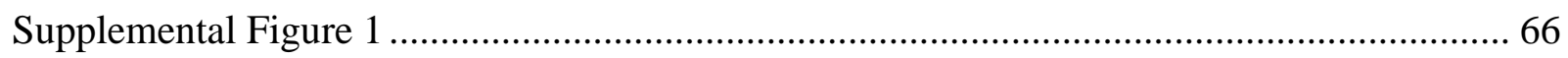

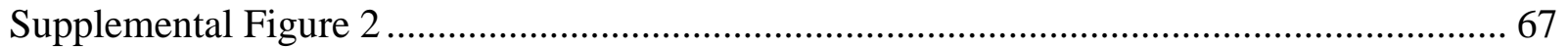

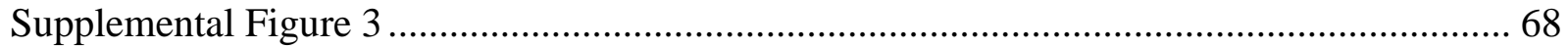

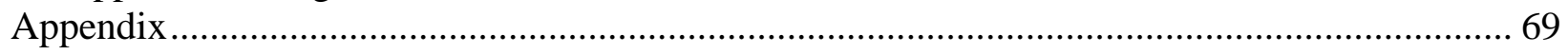

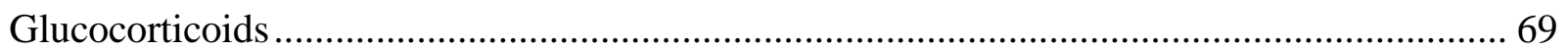




\section{CHAPTER 1. INTRODUCTION}

\subsection{Background and Significance}

Type 2 Diabetes Mellitus (T2DM) is a metabolic disorder in which insulin resistance occurs in the peripheral tissues causing a disruption in the uptake and storage of fuel substrates ${ }^{1}$. T2DM is reaching epidemic proportions and the prevalence of the disease is on the rise. By the year 2030 it is projected that 439 million people worldwide will be living with diabetes ${ }^{2}$. The cause of this increase in diabetes prevalence is likely due to an aging population and an increase in overall population size ${ }^{3}$. In addition; obesity, increasing sedentary lifestyles and poor dietary choices are known to cause metabolic disturbances that lead to T2DM ${ }^{4}$.

Increasing evidence has indicated that prolonged stress could be another contributing factor to the onset of T2DM, through increased activation of the hypothalamic-pituitary-adrenal (HPA) axis causing increased levels of stress hormones ${ }^{5}$. Psychological stress has long been suspected of being linked with diabetes development ${ }^{6}$. Anxiety and depression are known to increase the risk of acquiring $\mathrm{T} 2 \mathrm{DM}{ }^{7,8}$. Often depressed patients have increased levels of cortisol $^{9}$ and chronically high glucocorticoid (GC) levels cause enhanced hepatic gluconeogenesis, increased circulating glucose levels, protein degradation, and antagonize the effects of growth hormone and insulin ${ }^{105}$.

Along with changes to peripheral tissues, GC's also stimulate the insulin producing $\beta$ cells that are located in the islets of Langerhans to increase their mass in order to maintain glucose homeostasis ${ }^{11}$. This increase in $\beta$-cell mass is a healthy response to various stimuli that cause an increased glucose challenge and is called compensation ${ }^{12} \cdot \beta$-cell compensation is often seen in obese individuals and $\beta$-cell mass can reflect whole body adiposity and insulin resistance ${ }^{11}$. $\beta$-cell mass increases are due to individual $\beta$-cells increasing their size and/or cell regeneration within the islet ${ }^{12}$. Within a healthy islet, $\beta$-cell mass is maintained through a 
continuous balance of cell replication, neogenesis, and apoptosis ${ }^{11}$. If this balance becomes abnormal or compensation continues for an extended period of time $\beta$-cell dysfunction could occur, resulting in a reduction in $\beta$-cell mass through apoptosis ${ }^{13}$ or exhaustion of insulin release ${ }^{12,14}$. Individuals that have dysfunctional $\beta$-cells could be diagnosed as pre-diabetic; with prolonged dysfunction resulting in $\mathrm{T} 2 \mathrm{DM}{ }^{12,15}$. The mechanisms leading to dysfunction from compensation are not fully known, however, increased exposure to free fatty acids and glucose have been shown to affect $\beta$-cell function, both of which are influenced by GCs and physical activity levels ${ }^{16-18}$.

GCs exert metabolic effects throughout the periphery on numerous different target tissues, including skeletal muscle ${ }^{19}$. Skeletal muscle contributes to maintaining euglycemia by serving as a glycogen reservoir. In times of stress, GCs may be released in excess which could be detrimental to skeletal muscle by inducing muscle atrophy and insulin resistance ${ }^{19}$. GCs cause an altered translocation of GLUT-4 in skeletal muscle which inhibits glucose uptake and glycogen synthesis ${ }^{20-22}$. Insulin signaling is also interrupted by excess GCs as evidenced by reduced insulin receptor (IR) and insulin receptor substrate 1 (IRS-1) proteins in mouse muscle treated with GCs ${ }^{21}$. Furthermore, the activity of phosphoinositide-3-kinase (PI3K) and Akt, which serve as downstream signaling molecules to IR and IRS-1 exhibit reduced activity ${ }^{21,23,24}$. Protein degradation occurs in parallel to the insulin signaling defects as a result of excess GCs. Numerous studies have demonstrated that treating animals with synthetic GCs results in a reduction of muscle mass ${ }^{25-28}$. There are a number of genes that have been discovered to be upregulated during times of muscle wasting that are called atrogenes ${ }^{29}$. Muscle RING finger 1 (MuRF1) and muscle atrophy F-box (MAF-bx) are well known atrogenes and have increased gene expression during many muscle wasting situations including T2DM ${ }^{30}$. Furthermore, during 
synthetic GC injection, there are increases in levels of the autophagy proteins that along with the atrogenes could contribute to increased muscle atrophy ${ }^{31}$.

Exercise training has long been established as having protective effects against T2DM development and has been shown to reduce the risk of T2DM in both humans ${ }^{32-34}$ and rodents 35-37. Regular exercise increases GLUT-4 translocation in working skeletal muscle which promotes maintenance of normal glucose levels ${ }^{38}$. Increases in muscle insulin sensitivity are also seen with regular exercise, which decreases the amount of insulin that needs to be released by the $\beta$-cells. It has been hypothesized that these changes to skeletal muscle prevent $\beta$-cell exhaustion by means of preserving $\beta$-cell mass ${ }^{11}$. In addition to effects on $\beta$-cells, regular exercise is known to upregulate the Akt/mTOR pathway thus inhibiting skeletal muscle proteolysis and preventing muscle wasting ${ }^{39}$.

Increased GC levels have been induced through the use of synthetic dexamethasone or exogenous GCs in order to elucidate their effects ${ }^{21,22,40}$. A possible alternative model to induce increased levels of circulating GCs and mimic a prediabetic state is through the use of a Chronic Mild Stress (CMS) model. CMS has been shown to cause anxiety, depression, increased levels of corticotrophin releasing factor (CRF), increased circulating corticosterone and glucose intolerance ${ }^{41,42}$. Through the use of a CMS model this thesis seeks to examine the effect of stress on $\beta$ cell morphology and skeletal muscle. In addition to this, exercise has been shown to provide many positive counter effects to increased circulating GCs and will be examined in combination with CMS to determine if it can serve as an effective counter measure to the detrimental effects of stress. 


\subsection{Purpose and Specific Aims}

To date no research has been published that determines to what extent a method of stressing animals, such as Chronic Mild Stress (CMS) model, effects $\beta$ cell morphology and muscle atrogene expression. In addition, the effects of CMS and voluntary exercise administered in combination are largely unknown. The purpose of this thesis is to examine the combined effects of CMS and exercise on $\beta$ cell morphology and skeletal muscle atrophy and autophagy.

Specific Aim 1. Determine the effect of 8 weeks of CMS and exercise on pancreatic $\beta$ cell morphology.

Hypothesis 1. CMS alone will cause an increase in $\beta$-cell number per islet and islet area. Hypothesis 1.2. CMS in combination with exercise will result in an attenuation of $\beta$ cell number and islet area increases.

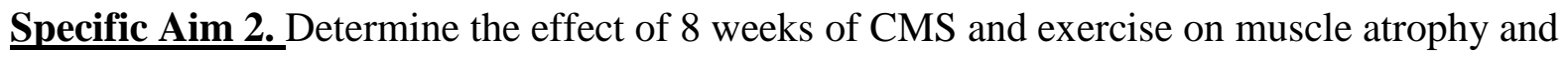
ubiquitin proteolysis gene expression.

Hypothesis 2.1. CMS alone will cause an atrophic effect, thus reducing muscle mass and causing an increase in gene expression of the muscle atrophy associated genes Murf-1 and MAFbx.

Hypothesis 2.2. CMS in combination with exercise will prevent a loss in muscle mass and will attenuate MuRF-1 and MAFbx gene expression.

Specific Aim 3. Determine the effect of 8 weeks of CMS and exercise on protein markers of autophagy; Beclin-1, ATG-7 and LC3a/b.

Hypothesis 3.1 CMS alone will cause an increase in all measured autophagy protein markers. 
Hypothesis 3.2. CMS in combination with exercise will prevent a loss in muscle mass and will have attenuated Beclin-1, ATG-7 and LC3a/b levels. 


\section{CHAPTER 2. REVIEW OF LITERATURE}

\subsection{Stress response}

Stress and anxiety have been shown to be possible factors for increased risk of T2DM, due to the accompanying metabolic disturbances they cause ${ }^{43}$. A wide range of stressful situations like chronic work stress, low socioeconomic status ${ }^{44,45}$, anxiety, and depression ${ }^{46}$, could potentially elicit undesirable neuroendocrine responses. Hans Selye a pioneer in determining the physiologic response to stress, defined stress as "the nonspecific response of the body to any demand" ${ }^{\prime 4}$. Stress can be broadly categorized into 3 categories: 1) psychological stressors (fear, anxiety, exposure to a novel or uncontrollable environment); 2) stressors combining a physical stimulus with a strong psychological component (pain, foot shock, immobilization); 3) challenges to cardiovascular homeostasis (hemorrhage, exercise, heat exposure, orthostatic stress/upright tilt $)^{48}$. When presented with various stressors that become a threat to homeostasis a healthy individual will respond by activation of the stress response ${ }^{49,50}$. The stress response can occur through behavior modification, increased neural output, increased secretion of hormones or a combination of all three ${ }^{49}$. There are two main brain circuits that initiate and maintain the stress response system; the hypothalamic pituitary adrenal (HPA) axis and the sympathetic nervous system ${ }^{51}$. These circuits are located and centrally mediated through the hypothalamus and the brainstem ${ }^{52}$ and ultimately influence the level of glucocorticoids that will be released into the systemic circulation.

\section{HPA Axis}

Under basal conditions the hypothalamus secrets corticotrophin releasing factor (CRH) and arginine-vasopressin (AVP) into the hypophyseal portal system, in a diurnal pulsatile fashion with a burst of secretion every 2-3 hours ${ }^{52}$. These two hormones function synergistically, with AVP causing increased release of $\mathrm{CRH}$. The peak release levels in humans occur in the early 
morning hours and decrease throughout the day. In rodents this release cycle is opposite due to their nocturnal nature and their levels peak at night and decrease as the night goes on into the early morning hours. When faced with a stressor the system is activated quickly and peak GC release occurs in 15 to 30 minutes with a gradual wane in release lasting up to two hours post stressor ${ }^{53}$. Influences such as lighting, food intake, activity levels, and stressful situations can alter the pulsatile release schedule of CRH and AVP thus altering adrenocorticotropic hormone (ACTH) release from the anterior pituitary ${ }^{52}$.

When challenged with a stressful situation or through psychological preparation for an upcoming high stress event, the HPA axis is rapidly activated and has far reaching effects throughout the body. These far reaching effects are mainly due to the abundance of the glucocorticoid receptor $(\mathrm{GR})^{53}$. The hypothalamus mediates the stress response through the release of corticotrophin releasing hormone $(\mathrm{CRH})$ which stimulates the anterior pituitary to release ACTH. Circulating ACTH is a key regulator of the release of glucocorticoids from the adrenal cortex. The subsequent release of GCs, mainly cortisol in humans and corticosterone in rodents, from the adrenal glands, is essentially the final product of the HPA axis. Upon exerting its effects throughout the animal, cortisol also functions as a potent inhibitor of further anterior pituitary release of ACTH, thus inhibiting further cortisol release. The inhibitory function of cortisol is critical in order to prevent long exposure to increased glucocorticoid levels which could be harmful due to their catabolic, anti-reproductive and immunosuppressant effects ${ }^{53}$. The binding of GC to GR in the prefrontal cortex and hippocampal brain regions serves as a braking system to HPA axis activation. The HPA axis is critical for survival and adaptation, healthy individuals will respond to the increasing levels of glucocorticoids in a concentration dependent manner that results in an "inverted U-shape" graph when glucocorticoid levels are plotted against 
level of adaptation (see figure below) ${ }^{54}$. Counter to this, too much GCs without a properly functioning inhibitory feedback system can lead to many detrimental effects.

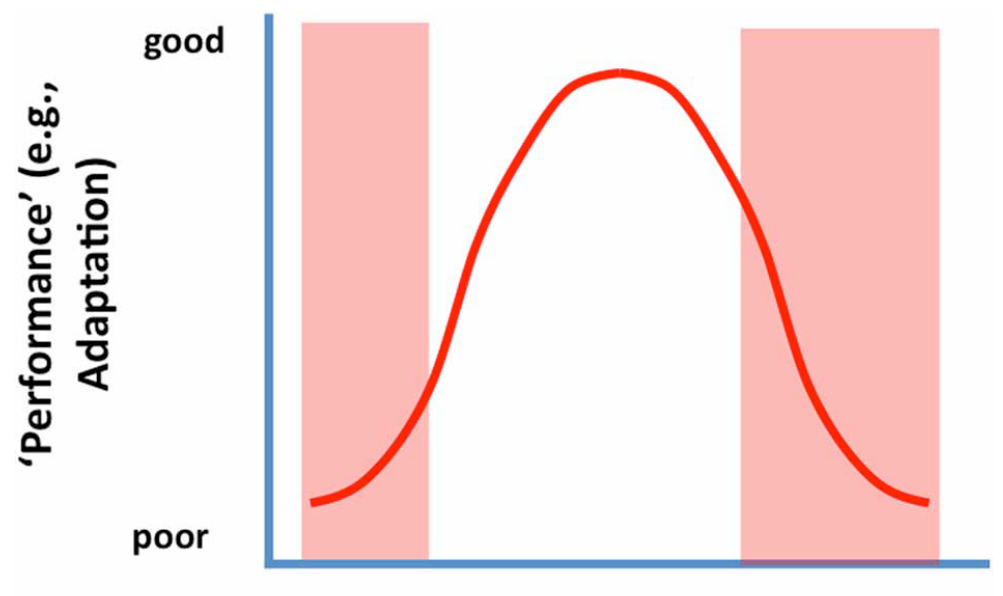

\section{Physiologic Response}

(e.g., Glucocorticoid Levels)

\section{Dysfunction of the HPA}

The stress response and its effectiveness are highly temporal in nature with its subsequent activation meant to last only for an acute time frame. Chronic activation of the HPA can result in detrimental effects such as; anti-reproduction, catabolism, and immunosuppression ${ }^{52}$. It is critical to understand that when an organism is faced with chronic stress there is a cross over from adaptive response to a maladaptive response. These maladaptive responses are believed to be the result of chronic stress causing a major structural shakeup in the workings of the HPA axis. Chronic stress can lead to hyperactivation of the HPA with increases seen in CRH and AVP in paraventricular nucleus $(\mathrm{PVN})$ neurons ${ }^{53}$. Accompanying the hyperactivation of the stress response is a diminished inhibition effect. The HPA axis in healthy individuals is rapidly inhibited by the rising levels of GC that bind to GR in the prefrontal cortex (PFC) and hippocampus. Glucocorticoids injected directly into the PFC result in decreased HPA axis activity $^{55}$. In a maladaptive state, which features times of chronic activation of the HPA, the GR expression levels in the prefrontal cortex and hippocampus have been shown to be reduced ${ }^{56}$. 
There is also evidence that as the HPA axis becomes dysfunctional through chronic activation there could be a feed forward mechanism at work which would cause a maladaptive response to stress. This feed forward mechanism is believed to occur in the central nucleus of the amygdala which serves to inhibit the inhibitory relay neurons signaling the $\mathrm{PFC}^{53}$ in times of chronic stress. The end result of the dysfunctional responses of the HPA in times of chronic stress is an increase in the amount of circulating GCs.

\subsection{The chronic mild stress model}

The CMS model was developed by Wilner and colleagues in order to create an animal model that is a valid simulation of a chronic state of depression ${ }^{57}$. The CMS model features various mild stressors (predator noises, constant cage shaking, damp bedding, no bedding, water in the cage, tilted cage and altered light dark cycle) applied every few hours and repeatedly over the course of weeks or months. The CMS model has proven its ability to serve as a valid model for animal depression. Much of this validity is based upon the CMS models ability to induce anhedonia in rodents ${ }^{57}$. Anhedonia is the lack of responsiveness to pleasurable events; this is measured in the CMS model through rodent's sucrose preference in drinking water ${ }^{57}$. CMS has been used extensively in the study of the effectiveness of current antidepressive drugs and the discovery of new antidepressive treatment ${ }^{57}$. CMS has been shown to cause increased levels of corticotrophin releasing factor (CRF), increased circulating corticosterone and glucose intolerance $^{41,42}$. An additional use of CMS could be to examine the association among depression and T2DM. It has been found that there is a bidirectional relationship between depression and T2DM with depressed individuals having increased incidence of diabetes and vice versa ${ }^{7,8}$.

Phenotypically rodents subjected to CMS typically show a reduced coat state, which is a score of 1-4 given to each animal by two independent observers and is based on the overall state 
of the animals coat ${ }^{41,58}$. In addition, the sex and strain of the mouse is also highly important as different strains will adapt more favorably or less favorably throughout the time course of the study $^{58}$. It has been previously shown that male C57B1/J6 mice have the greatest outward detrimental effect to the fur which is indicative of increased stress ${ }^{58}$. This indicates that not all mice will respond to the same degree to CMS and that care should be taken when choosing a strain so that the stress will provide maximal effect.

\section{Glucocorticoid relationship to metabolic pathologies}

Genetic and environmental factors can cause alterations in GR function and result in GC resistance. Possible environmental factors that lead to GC resistance would include chronic inflammation, exposure to infectious agents, chronic exposure to exogenous glucocorticoids (dexamethasone), and chronic stress exposure ${ }^{59}$. There has been a suspected link between stress and metabolic disorders for quite some time. Acute stress as mentioned before causes elevations in GCs which help an organism regain homeostasis. However, with an increased timeframe of stress and the introduction of chronically high GC levels, dysfunction can arise in the GC/GR signaling complex which can lead to detrimental effects for the organism as a result of glucocorticoid resistance ${ }^{59}$. Increased stress levels and elevated GCs in humans have been convincingly linked to coronary heart disease ${ }^{60}$. There could also be an association between stress and metabolic syndrome or even $\mathrm{T} 2 \mathrm{DM}^{61}$. Metabolic syndrome presents as hyperglycemia, abdominal obesity, elevated triglycerides, and high blood pressure ${ }^{43}$. These abnormalities are also known to occur in Cushing's syndrome in which individuals are over producing cortisol. Thus many studies have tried to focus on the pathogenesis of metabolic syndrome and how stress or alterations in GC levels can cause individuals to exhibit a metabolic syndrome like state. Many individuals who present with metabolic syndrome have been found to have a hyperactive 
HPA axis and hypercortisolism ${ }^{43}$. This hypothesis has been very difficult to confirm due to the many factors contributing to the stress response and differences between how individuals respond to stress. Nonetheless, it has been found that cortisol controls many aspects of adipose tissue and when in excess can cause visceral adiposity ${ }^{62}$. Excessive GC levels promote lipoprotein lipase which results in the increase in circulating FFA, accumulation of triglycerides in adipocytes, and possible lipotoxicity in peripheral tissues ${ }^{63}$. Continual metabolic effects of chronically elevated GCs could promote a vicious cycle of inflammation, a contributing factor in the pathogenesis of metabolic syndrome. The increased cytokines from this state could lead to symptoms in which an organism is shifted toward behavioral depression with reduced locomotor activity and increased sleep; in order to conserve energy for further immune activation ${ }^{59}$. Metabolically, chronically elevated GCs cause a multitude of problems which can lead to pathologies if not treated. In addition to the metabolic effects of elevated GCs, they also exert their effects on two important tissues that serve as the main pathological focus of the occurrence of T2DM; muscle and pancreatic $\beta$ cells. The effect of chronically activated HPA and increased GC levels and their direct and indirect effect on these two tissues will be covered in the following sections.

\section{Direct Effect of GCs on Muscle}

Skeletal muscle is unique in that much like the liver, it serves as a large glucose storage depot helping to prevent hyperglycemia. Skeletal muscles role in glucose metabolism is critical as it is accountable for $80 \%$ of postprandial glucose uptake from the circulation ${ }^{64}$. The glucose storing capacity of muscle can be negatively affected when there is insulin insufficiency or disruptions in insulin signaling. This was first observed over 75 years ago by Sir Harold Himsworth who discovered a large number of patients with diabetes were "insulin insensitive"65. GCs effect on muscle glucose uptake can be most clearly seen in cases where GCs are in excess 
such as exogenous administration or Cushing's syndrome. Henriksen et al. demonstrated this by administering exogenous GC (dexamethasone) to healthy subjects over a 5 day period and observed reduced glycogen synthesis rates and decreased glycogen synthase concentrations and activity within skeletal muscle ${ }^{66}$. Further GC treated skeletal muscle alterations were shown by Tomlinson et al. who showed reduced expression and phosphorylation of insulin receptor substrate-1 (IRS-1), phosphatidylinositol 3-kinase (PI3-k), and protein kinase b (PKB)/Akt and the translocation of GLUT-4 to the cell surface ${ }^{21}$.

In addition to the altered glucose homeostasis present during excessive levels of GCs in skeletal muscle, there is also an increase in skeletal muscle atrophy. Atrophy of skeletal muscle is characterized by a decrease in the size of muscle fibers. There are a number of pathological states in which muscle atrophy occurs and is associated with an increase in circulating GC levels (sepsis, cachexia, starvation, metabolic acidosis, and severe insulinopenia) ${ }^{67}$. Elevations in circulating levels of GCs increase protein breakdown and decrease protein synthesis. In animal models of GC induced atrophy, the age of the animal plays a role in whether increased protein breakdown or decreased protein synthesis will result in atrophy. Dardevet et al. found that in adult rats increased protein breakdown led to atrophy whereas aged rats saw depressed protein synthesis $^{68}$.

Glucocorticoids stimulate skeletal muscle atrophy through the activation of the ubiquitin proteasome system (UPS), the lysosomal system (autophagy) or the calcium dependent system (calpains) ${ }^{67}$. It was discovered by Tiao et al. that protein degradation due to GCs mainly causes degradation of the myofibrillar proteins and extracellular matrix proteins. The ubiquitin proteasome system is known to degrade protein through two steps: 1) tagging the substrate by covalent attachment with many ubiquitin molecules and 2) degradation of the tagged protein by 
the $26 \mathrm{~S}$ proteasome complex with recycling of ubiquitin ${ }^{69}$. Of importance for this thesis, GC have been linked to the expression of several components of the UPS namely the atrogenes, MuRF-1 and MAFbx also known as Atrogin- $1^{29}$. Furthermore, GC are directly involved in upregulating proteasome activity $^{70}$. The atrogenes MuRF1 and MAFbx are muscle specific E3 ubiquitin-ligases and are increased in most catabolic scenarios, including denervation, nutritional deprivation, unloading and exogenous GC treatment ${ }^{19}$. These E3 ubiquitin-ligases are the mediators of the ubiquitination process that occurs prior to degradation by the $26 \mathrm{~S}$ proteasome. MuRF-1 and MAFbx knockout (KO) animals have been used to determine if muscle mass loss can be attenuated when muscles are denervated. Bodine et al. found that during denervation, the $\mathrm{KO}$ animals did have attenuations in muscle mass loss, however when exposed to exogenous GC only MuRF-1 KO's and not MAFbx KO had attenuated muscle atrophy ${ }^{29}$. Additionally MuRF-1 has been shown to play a role in myosin heavy chain ubiquitination and degradation during dexamethasone treatment ${ }^{71}$. These atrogenes are thought to be regulated through the increased expression of FOXO1 and $\mathrm{FOXO} 3 \alpha$, whose transcription is regulated by GC. The involvement of FOXO1 transcriptional activation by GC has been shown in vitro, but there is not yet direct in vivo evidence for the necessity of FOXO to be involved in GC related muscle atrophy.

\subsection{Autophagy}

Classically, autophagy's function has been known to degrade cytoplasmic components, protein aggregates, and/or organelles, serving as a tool for nutrient breakdown and a means to regulate the cellular architecture ${ }^{72}$. This occurs through the sequestration of the worn out cytoplasmic organelles in a vacuole called the autophagosome. Following the sequestration, the autophagosome fuses with a lysosome that degrades the vacuole products by lyososomal hydrolases $^{73}$. Autophagy is crucial for survival as whole body $\mathrm{KO}$ of autophagy protein 12 (ATG-12) in mice has proven to be lethal ${ }^{74}$. Skeletal muscle cellular components are frequently 
being damaged due to the high amounts of reactive oxygen species produced within the muscle. Autophagy serves as a cellular remodeling agent providing a route for damaged or worn out organelles to be recycled and also serves to provide energy needs of the body through the breakdown of protein ${ }^{72}$. There is recent evidence that suggests there is a possible link between autophagy and GC induced muscle atrophy. GC induced muscle atrophy has been discovered to be mediated not only through the UPS, but possibly through autophagic-lysosomal proteolysis ${ }^{75}$.

The proposed link between GC and skeletal muscle autophagy has been made through the FOXO3 $\alpha$ pathway ${ }^{76}$. This is of interest because FOXO3 drives the expression of autophagic genes such as microtubule-associated protein 1 light chain 3 (LC3), vacuolar protein sorting (Vps34), Atg12, and GABA(A) receptor-associated protein (GABARAP) ${ }^{72}$. Following the activation of FoxO3 by GC the Atg proteins and other cellular pathways control autophagy which is broken down into three steps: 1)initiation, 2) nucleation/autophagosome formation, and 3) lysosome fusion/degredation ${ }^{72}$. Initiation is mediated through ULK1 not being phosphorylated by mTOR which allows ULK1 to initate phagophore nucleation. Initiation can also occur through interactions of Bcl-2 and the Beclin-1 initiation complex ${ }^{72}$. The nucleation of the phagophore is occurring due to the complexation of Beclin-1 with various autophagy proteins (Atg14, Vps15, UVRAG, Rubicon, class III PI3K) ${ }^{72}$. This Beclin-1 complex produces the nucleating lipid species PI3P which results in elongation of the phagophore. Nucleation also involves the E1 and E2 ubiquitin ligases, Atg7, and $\operatorname{Atg} 10^{72}$. Furthermore there is involvement of Atg 5 being conjugated to the ubiquitin like Atg12 and conjugation of phosphatidylethanolamine to LC3I to form Atg8/LC3II. The mature autophagosome is now able to sequester cytoplasm, proteins, and organelles, for their subsequent delivery to the lysosome where they are degraded. The levels of LC3I to LC3II and also increased Beclin-1 levels have been used as indicators of 
autophagy induction ${ }^{72}$. Although autophagy is considered a good thing in healthy and wellfunctioning muscle, few studies have examined the effect that autophagy plays in a muscle wasting model such as cancer or dexamethasone administration. One of the few studies to do so was Penna et al. who examined autophagy proteins involved in dexamethasone injected mice and C26 tumor bearing mice. Following just 7 days of dexamethasone injection the levels of Beclin-1 and LC3B were significantly increased in the tibialis anterior along with overall losses in skeletal muscle mass ${ }^{31}$. These results indicate that autophagy could contribute to skeletal muscle atrophy in a model of dexamethasone injection or elevated GC levels.

\subsection{Direct and indirect effects of GCs on Islet morphology and function}

The $\beta$ cells of the islet of Langerhans are essential for maintaining euglycemia.

Euglycemia is maintained by $\beta$ cells releasing insulin in response to rising blood glucose levels. Insulin release occurs in two phases with the first phase occurring 8-10 minutes after a meal is ingested $^{77}$. This is followed by a longer lasting second phase that occurs $30-45$ minutes after meal ingestion ${ }^{78}$. Impairment of beta cell function is clinically considered pre-diabetes if the blood glucose levels are not lowered to basal levels within 2 hours following a meal ${ }^{11}$. The increased time course to lower blood glucose could be due to $\beta$ cell dysfunction, characterized by $\beta$ cells themselves becoming desensitized to glucose or insulin signaling ${ }^{11}$.

$\beta$ cell mass is in a dynamic balance in the healthy non-diabetic individual due to ever changing levels of $\beta$ cell apoptosis, replication, and neogenesis ${ }^{11} . \beta$ cell mass is highly important due to its reflection of whole body adiposity and insulin resistance ${ }^{11}$. Naturally if the delicate balance between apoptosis, replication and neogensis is disrupted pathologies could arise. It has been found by Butler et al. that T2DM patients have increased levels of apoptosis occurring in $\beta$ cells $^{13}$. Apoptosis is necessary for healthy $\beta$ cell mass expansion; however when present in exceeding amounts can greatly reduce the ability of the $\beta$ cells to produce the correct amount of 
insulin. As the pathology of T2DM arises the $\beta$ cells are thought to go through a cycle of compensation which entails their expansion due to the increased peripheral insulin resistance, thus stimulating them to proliferate or increase in individual size, resulting in more insulin production. Following this expansion phase of the cycle is the phase Beaudry et al. terms dysfunction. This phase is characterized by reduced insulin release although some individuals are able to maintain euglycemia and not become hyperglycemic ${ }^{79}$. Subsequently, the $\beta$ cells become reduced in mass. It is hypothesized that this is what Butler et al. observed in their study of T2DM patients. At this point of the $\beta$ cell mass/life cycle the individual is not yet insulin dependent, so the $\beta$ cells are still producing insulin but it is certainly not sufficient for preventing hyperglycemia. The final phase of the life cycle is the $\beta$ cell exhaustion phase where the patient becomes insulin dependent due to the $\beta$ cells not being able to produce enough insulin ${ }^{12}$. The alpha cell also plays an intimate role with the $\beta$ cell as it also makes up the islet of Langerhans. The $\alpha$ cells release glucagon that signals the liver to increase glucose production and causes a rise in blood glucose. $\alpha$ cells have been found to be in higher numbers in individuals who are T2DM. Signaling between $\alpha$ and $\beta$ cells is thought to be altered in individuals with T2DM.

\section{Short term GC exposure}

The $\beta$ cells mass expands through hypertrophy or hyperplasia in order to overcome peripheral insulin resistance by increasing production of insulin. As a result of peripheral insulin resistance there is a detrimental effect of excess cellular glucose and lipids on the $\beta$ cell that affects their function ${ }^{80}$. Increased glucose levels result in decreased $\beta$ cell survival, decreased insulin synthesis, and impairment of insulin signaling ${ }^{81}$. The effect of increased glucose on $\beta$ cells have been well established, however very few studies have examined the direct effect of excess GCs on $\beta$ cell function. The direct effect of GCs on $\beta$ cells is thought to be highly temporal in nature with differing detriments for the short term and chronic timeframes. GCs 
affect many of the same receptors in $\beta$ cells as they do in skeletal muscle, thus $\beta$ cells face similar alterations that skeletal muscles undergo in glucose transport and insulin signaling.

Glucose is sensed and taken up by the $\beta$ cell much like it is any other cell in the body, through a GLUT transporter. Many diabetic models have found that a reduction of GLUT-2 expression could be indicative of a loss of $\beta$ cell function, which results in lower glucose uptake and less insulin release ${ }^{11}$. There is evidence of insulin resistance in the periphery in these models but at the same time there is altered insulin release at the level of the $\beta$ cell. Whether the effects are at the periphery or at the $\beta$ cell directly, the short term effect of GCs causes expansion of $\beta$ cell mass by what is thought to be increased $\beta$ cell to cell communication within the islet. This was shown by Rafacho et al., where there was an increase in $\beta$ cell exclusive gap junction protein connexon $36^{82}$. This increase in connexon 36 was due to just 5 days of dexamethasone treatment ${ }^{82}$. In vitro studies to test the direct effect of glucocorticoids were carried out by Jeung et al. who exposed $\beta$ cells to increasing concentrations of dexamethasone (1-100 nmol/L) over a a 6 hour period. The $\beta$ cell function was impaired as evidenced by a significantly down regulated insulin synthesis levels $^{83}$. In addition to this, Lambillotte et al. and Gremlich et al. found similar results in that $\beta$ cells had reduced insulin secretory capacity and insulin release ${ }^{84}$. However, one drawback to any dexamethasone model is that it binds with $\sim 10$ fold higher affinity to the GR than naturally occurring GCs ${ }^{11}$. It is evident from the data that $\beta$ cells respond differently in vivo and in vitro to the short term exposure to GCs. The expansion and increased glucose sensing ability of $\beta$ cells in vivo differs in vitro where the $\beta$ cells become dysfunctional in their glucose sensing mechanisms after short periods of dexamethasone exposure.

\section{Prolonged and Intermittent GC exposure to $\boldsymbol{\beta}$ cells}

Prolonged treatment with a synthetic GC drug such as prednisone can cause the aforementioned changes in peripheral tissues such as widespread insulin resistance which 
changes the environment (increased blood glucose and lipids) that the $\beta$ cells must deal with. Healthy individuals that undergo prolonged GC treatment are able to resist diabetes development by $\beta$ cell expansion and increasing glucose stimulated insulin secretion (GSIS) ${ }^{85}$. However, without adequate compensation of the $\beta$ cells, hyperglycemia could develop and lead to T2DM. The alterations in these cells that cause dysfunction and not expansion with prolonged exposure are thought to be due to a reduced GSIS involving the first phase insulin response. This response is severely blunted and appears to be due to GC affecting the calcium influx of the $\beta$ cell which is needed for insulin secretion ${ }^{11}$. In addition, if the $\beta$ cells cannot respond to the peripheral insulin resistance or increased hepatic glucose production it has been hypothesized that the cells become exhausted and apoptosis results ${ }^{12}$. It is critical to determine the time-point of $\beta$ cell expansion or decompensation with prolonged periods of stress.

Diabetes has often been linked to psychological stress due to its effects on metabolic activity ${ }^{61}$. Bates et al. and Kiraly et al. focused on whether intermittent stress would act as a protective factor in preventing $\beta$ cell loss or contribute to $\beta$ cells deterioration in the Zucker Diabetic Fatty (ZDF) rat. Bates et al. used rat restraint stressing for $1 \mathrm{hr}$ day/5 days wk/ over varying periods of 3,6 , or 13 weeks, to determine if intermittent stress could maintain beta cell compensation in the ZDF rat. The stress resulted in increased number of islets $/ \mathrm{mm}^{2}$ of pancreas after 13 wks whereas the non-stressed ZDF rats experienced a significant reduction in islet number compared with control rats ${ }^{86}$. Kiraly et al. found similar protective effects of stress for the ZDF rat when the rats were stressed by being placed in water for $1 \mathrm{hr}$ day/5 days wk/ 7 wks. The stress resulted in improved fed and fasting glucose tolerance in the stressed rats compared to the control animals ${ }^{87}$. Additionally, the intermittent stress produced significantly higher levels of corticosterone in stressed ZDF rats when compared to a forced swim exercise group that 
exercised $1 \mathrm{hr}$ day $/ 5$ days $w \mathrm{k} / 7 \mathrm{wks}^{87}$. Kiraly et al. proposed that there could have been minute changes in body composition such as reduced fat pad mass, that they did not account for in their study which could have resulted in the improved fed and fasting glucose profiles ${ }^{87}$. In addition Kiraly et al. speculated that the protective effect of stress could be due to inhibition of insulin secretion which would slow the beta cell decomposition process ${ }^{87}$. Perhaps these intermittent stress regiments resulted in glucocorticoids not being chronically elevated. Thus the results seen in this study differ drastically from those of dexamethasone treatment effects on the $\beta$ cells. To date there has been no study to examine the effect of CMS on a healthy animal's islet morphology over a chronic timeframe. This model would differ from what Kiraly and Bates et al. have previously shown where the stress is applied to an animal that is progressing into overt diabetes through the ZDF model. An increased level of stress and perhaps longer timeframe could induce similar damage to that seen when synthetic GCs are administered.

\subsection{Exercise during stress and diabetes}

Exercise as medicine has become an increasingly popular theme as diabetes and obesity reach near epidemic levels worldwide. Exercise is a well-established means to improve blood glucose control in both healthy and diabetic individuals ${ }^{88,89}$. In further support of this, regular exercise training regimen in humans with T2DM has been shown to improve insulin response to hyperglycemia ${ }^{90}$. A crucial benefit of exercise is that it has the ability to directly affect the $\beta$ cells of the pancreas and has been shown in numerous animal models to cause an improved potential for insulin secretion ${ }^{91-93}$. Kiraly et al. demonstrated this by swim training ZDF rats for $1 \mathrm{hr} /$ day/5days/wk over a 13 week period. Following the 13 weeks of training exercised ZDF rats had attenuated losses to $\beta$ cells through compensation by increased $\beta$ cell proliferation, new insulin positive clusters (neogenesis), and $\beta$ cell hypertrophy ${ }^{6}$. Although these exercise effects 
can be seen as occurring at the level of the $\beta$ cells it is important to not overlook the influence of exercise effects on the peripheral tissues.

Exercise can activate GLUT-4 transporters in skeletal muscle which are stimulated via muscle contraction and transport glucose from the blood to the muscle which results in improved blood glucose maintenance. Regular exercise training leads to increased expression of GLUT-4 in skeletal muscle, which is associated with improved insulin action and glucose metabolism. Furthermore, insulin sensitivity can be positively influenced by exercise training leading to increased signal transduction through the insulin receptor substrates 1 and 2 (IRS-1 and IRS-2) ${ }^{89}$. This increased signal transduction is also important due to its role in protein synthesis and prevention of protein degradation. The increased IRS signaling results in the phosphorylation of Akt which inhibits protein degradation through repression of transcription factors of the FOXO family ${ }^{94}$. Additionally the increased phosphorylation of Akt can stimulate protein synthesis through mammalian target of rapamycin (mTOR) and glycogen synthase kinase 3B (GSK $\beta)^{94}$.

Short term exercise is known to act as a stressor and leads to increased levels of plasma glucocorticoids ${ }^{95}$ and catecholamines ${ }^{96}$. However, regular exercise has proven beneficial at reducing perceived stress and during times of increased stress, high amounts of physical activity are associated with better health ${ }^{97}$. Exercise has been examined in human subjects with clinical depression and anxiety and has been shown to improve mood and lessen anxiety sensitivity ${ }^{98}$. The converse has been demonstrated among military personnel wherein increased job stress and psychological distress were associated with lower levels of physical activity ${ }^{99}$. In further support of stress resulting in less voluntary drive to exercise, DeVallence et al. (work not yet published) discovered that mice that were stressed for a 8 week period voluntarily exercised less than nonstressed control mice. 
Depression and anxiety are known to cause increased incidence of $\mathrm{T}_{2} \mathrm{DM}^{7,8}$.

Additionally, stress in the form of depression and anxiety are believed to be reciprocally related to exercise. The studies that examine the combined effects of exercise and stress on mice are scarce, especially those examining the relationship between stress and exercise and there effects on $\beta$ cell health and T2DM development. The results from the known studies focused on the benefits of exercise in regards to hippocampal neurogenesis, and showed marked differences between stressed and stress exercise animals. In one such study stressed animals exhibited blunted hippocampal neurogenesis while animals exposed to exercise combine with stress alleviated this detrimental effect ${ }^{100}$. This thesis is novel and seeks to examine the combined effects of stress and exercise at the level of the skeletal muscle and $\beta$ cells of the pancreas. 


\section{REFERENCES}

1. Long, Y. C. AMP-activated protein kinase signaling in metabolic regulation. J. Clin. Invest. 116, 1776-1783 (2006).

2. Shaw, J. E., Sicree, R. A. \& Zimmet, P. Z. Global estimates of the prevalence of diabetes for 2010 and 2030. Diabetes Res. Clin. Pract. 87, 4-14 (2010).

3. Sicree, R. \& Shaw, J. Type 2 diabetes: An epidemic or not, and why it is happening. Diabetes Metab. Syndr. Clin. Res. Rev. 1, 75-81 (2007).

4. Burén, J. \& Eriksson, J. W. Is insulin resistance caused by defects in insulin's target cells or by a stressed mind? Diabetes Metab. Res. Rev. 21, 487-494 (2005).

5. Kyrou, I., Chrousos, G. P. \& Tsigos, C. Stress, Visceral Obesity, and Metabolic Complications. Ann. N. Y. Acad. Sci. 1083, 77-110 (2006).

6. Király, M. A. et al. Swim training prevents hyperglycemia in ZDF rats: mechanisms involved in the partial maintenance of beta-cell function. Am. J. Physiol. Endocrinol. Metab. 294, E271-283 (2008).

7. Mezuk, B., Eaton, W. W., Albrecht, S. \& Golden, S. H. Depression and Type 2 Diabetes Over the Lifespan A meta-analysis. Dia Care 31, 2383-2390 (2008).

8. Knol, M. J. et al. Depression as a risk factor for the onset of type 2 diabetes mellitus. A meta-analysis. Diabetologia 49, 837-845 (2006).

9. Steckler, T., Holsboer, F. \& Reul, J. M. Glucocorticoids and depression. Baillières Best Pr. Res. Clin. Endocrinol. Metab. 13, 597-614 (1999).

10. Li, L., Li, X., Zhou, W. \& Messina, J. L. Acute psychological stress results in the rapid development of insulin resistance. J. Endocrinol. 217, 175-184 (2013).

11. Beaudry, J. L. \& Riddell, M. C. Effects of glucocorticoids and exercise on pancreatic $\beta$-cell function and diabetes development. Diabetes Metab. Res. Rev. 28, 560-573 (2012).

12. Weir, G. C. \& Bonner-Weir, S. Five Stages of Evolving Beta-Cell Dysfunction During Progression to Diabetes. Diabetes 53, S16-S21 (2004).

13. Butler, A. E. et al. Beta-cell deficit and increased beta-cell apoptosis in humans with type 2 diabetes. Diabetes 52, 102-110 (2003).

14. Sachdeva, M. M. \& Stoffers, D. A. Minireview: Meeting the Demand for Insulin: Molecular Mechanisms of Adaptive Postnatal ß-Cell Mass Expansion. Mol. Endocrinol. 23, 747-758 (2009).

15. Mitrakou, A. et al. Role of Reduced Suppression of Glucose Production and Diminished Early Insulin Release in Impaired Glucose Tolerance. N. Engl. J. Med. 326, 22-29 (1992).

16. Bonner-Weir, S. beta-cell turnover: its assessment and implications. Diabetes 50 Suppl 1, S20-24 (2001).

17. Prentki, M. \& Corkey, B. E. Are the beta-cell signaling molecules malonyl-CoA and cystolic long-chain acyl-CoA implicated in multiple tissue defects of obesity and NIDDM? Diabetes 45, 273-283 (1996).

18. Van Raalte, D. H. \& Diamant, M. Glucolipotoxicity and beta cells in type 2 diabetes mellitus: target for durable therapy? Diabetes Res. Clin. Pract. 93 Suppl 1, S37-46 (2011).

19. Kuo, T., Harris, C. A. \& Wang, J.-C. Metabolic functions of glucocorticoid receptor in skeletal muscle. Mol. Cell. Endocrinol. (2013). doi:10.1016/j.mce.2013.03.003

20. Dimitriadis, G. et al. Effects of glucocorticoid excess on the sensitivity of glucose transport and metabolism to insulin in rat skeletal muscle. Biochem. J. 321, 707-712 (1997).

21. Morgan, S. A. et al. 11ß-Hydroxysteroid Dehydrogenase Type 1 Regulates GlucocorticoidInduced Insulin Resistance in Skeletal Muscle. Diabetes 58, 2506-2515 (2009). 
22. Weinstein, S. P., Wilson, C. M., Pritsker, A. \& Cushman, S. W. Dexamethasone inhibits insulin-stimulated recruitment of GLUt4 to the cell surface in rat skeletal muscle. Metabolism 47, 3-6 (1998).

23. Pivonello, R. et al. Pathophysiology of diabetes mellitus in Cushing's syndrome. Neuroendocrinology 92 Suppl 1, 77-81 (2010).

24. Saad, M. J., Folli, F., Kahn, J. A. \& Kahn, C. R. Modulation of insulin receptor, insulin receptor substrate-1, and phosphatidylinositol 3-kinase in liver and muscle of dexamethasone-treated rats. J. Clin. Invest. 92, 2065-2072 (1993).

25. Auclair, D., Garrel, D. R., Chaouki Zerouala, A. \& Ferland, L. H. Activation of the ubiquitin pathway in rat skeletal muscle by catabolic doses of glucocorticoids. Am. J. Physiol. 272, C1007-1016 (1997).

26. Baehr, L. M., Furlow, J. D. \& Bodine, S. C. Muscle sparing in muscle RING finger 1 null mice: response to synthetic glucocorticoids. J. Physiol. 589, 4759-4776 (2011).

27. Hu, Z., Wang, H., Lee, I. H., Du, J. \& Mitch, W. E. Endogenous glucocorticoids and impaired insulin signaling are both required to stimulate muscle wasting under pathophysiological conditions in mice. J. Clin. Invest. 119, 3059-3069 (2009).

28. Shimizu, N. et al. Crosstalk between glucocorticoid receptor and nutritional sensor mTOR in skeletal muscle. Cell Metab. 13, 170-182 (2011).

29. Bodine, S. C. et al. Identification of ubiquitin ligases required for skeletal muscle atrophy. Science 294, 1704-1708 (2001).

30. Li, Y.-P. et al. TNF-? acts via p38 MAPK to stimulate expression of the ubiquitin ligase atrogin1/MAFbx in skeletal muscle. FASEB J. Off. Publ. Fed. Am. Soc. Exp. Biol. 19, 362370 (2005).

31. Penna, F. et al. Autophagic Degradation Contributes to Muscle Wasting in Cancer Cachexia. Am. J. Pathol. 182, 1367-1378 (2013).

32. Heath, G. W. et al. Effects of exercise and lack of exercise on glucose tolerance and insulin sensitivity. J. Appl. Physiol. 55, 512-517 (1983).

33. Nilsen, V., Bakke, P. S. \& Gallefoss, F. Effects of lifestyle intervention in persons at risk for type 2 diabetes mellitus - results from a randomised, controlled trial. BMC Public Health 11, 893 (2011).

34. Reduction in the Incidence of Type 2 Diabetes with Lifestyle Intervention or Metformin. $N$. Engl. J. Med. 346, 393-403 (2002).

35. Campbell, J. E. et al. Regular exercise prevents the development of hyperglucocorticoidemia via adaptations in the brain and adrenal glands in male Zucker diabetic fatty rats. Am. J. Physiol. - Regul. Integr. Comp. Physiol. 299, R168-R176 (2010).

36. Coutinho, A. E., Campbell, J. E., Fediuc, S. \& Riddell, M. C. Effect of voluntary exercise on peripheral tissue glucocorticoid receptor content and the expression and activity of $11 \beta$ HSD1 in the Syrian hamster. J. Appl. Physiol. 100, 1483-1488 (2006).

37. Droste, S. K., Chandramohan, Y., Hill, L. E., Linthorst, A. C. E. \& Reul, J. M. H. M. Voluntary exercise impacts on the rat hypothalamic-pituitary-adrenocortical axis mainly at the adrenal level. Neuroendocrinology 86, 26-37 (2007).

38. Burr, J. F., Rowan, C. P., Jamnik, V. K. \& Riddell, M. C. The role of physical activity in type 2 diabetes prevention: physiological and practical perspectives. Phys. Sportsmed. 38, 72-82 (2010). 
39. Fujita, S. et al. Aerobic Exercise Overcomes the Age-Related Insulin Resistance of Muscle Protein Metabolism by Improving Endothelial Function and Akt/Mammalian Target of Rapamycin Signaling. Diabetes 56, 1615-1622 (2007).

40. Beaudry, J. L., D’Souza, A., Teich, T., Tsushima, R. \& Riddell, M. C. Exogenous glucocorticoids and a high-fat diet cause severe hyperglycemia and hyperinsulinemia and limit islet glucose responsiveness in young male Sprague-Dawley rats. Endocrinology (2013). doi:10.1210/en.2012-2114

41. Ayensu, W. K. et al. Effects of chronic mild stress on serum complement activity, saccharin preference, and corticosterone levels in Flinders lines of rats. Physiol. Behav. 57, 165-169 (1995).

42. Pan, Y., Zhang, W.-Y., Xia, X. \& Kong, L.-D. Effects of Icariin on Hypothalamic-PituitaryAdrenal Axis Action and Cytokine Levels in Stressed Sprague-Dawley Rats. Biol. Pharm. Bull. 29, 2399-2403 (2006).

43. Anagnostis, P., Athyros, V. G., Tziomalos, K., Karagiannis, A. \& Mikhailidis, D. P. The Pathogenetic Role of Cortisol in the Metabolic Syndrome: A Hypothesis. J. Clin. Endocrinol. Metab. 94, 2692-2701 (2009).

44. Eller, N. H., Netterstrøm, B. \& Hansen, Å. M. Psychosocial factors at home and at work and levels of salivary cortisol. Biol. Psychol. 73, 280-287 (2006).

45. Maier, R. Effects of short- and long-term unemployment on physical work capacity and on serum cortisol - Springer. at <http://link.springer.com/article/10.1007\%2Fs00420-005-00529/fulltext.html>

46. Kinder, L. S., Carnethon, M. R., Palaniappan, L. P., King, A. C. \& Fortmann, S. P. Depression and the Metabolic Syndrome in Young Adults: Findings From the Third National Health and Nutrition Examination Survey. Psychosom. Med. 66, 316-322 (2004).

47. Seyle, H. Forty years of stress research: principal remaining problems and misconceptions.

48. Van de Kar, L. D. \& Blair, M. L. Forebrain Pathways Mediating Stress-Induced Hormone Secretion. Front. Neuroendocrinol. 20, 1-48 (1999).

49. Carrasco, G. A. \& Van de Kar, L. D. Neuroendocrine pharmacology of stress. Eur. J. Pharmacol. 463, 235-272 (2003).

50. Chrousos GP \& Gold PW. The concepts of stress and stress system disorders: Overview of physical and behavioral homeostasis. JAMA 267, 1244-1252 (1992).

51. Chang, L. et al. Dysregulation of the hypothalamic-pituitary-adrenal (HPA) axis in irritable bowel syndrome. Neurogastroenterol. Motil. Off. J. Eur. Gastrointest. Motil. Soc. 21, 149159 (2009).

52. Tsigos, C. \& Chrousos, G. P. Hypothalamic-pituitary-adrenal axis, neuroendocrine factors and stress. J. Psychosom. Res. 53, 865-871 (2002).

53. Herman, J. P. Neural control of chronic stress adaptation. Front. Behav. Neurosci. 7, (2013).

54. Kloet, E. R. de, Vreugdenhil, E., Oitzl, M. S. \& Joëls, M. Brain Corticosteroid Receptor Balance in Health and Disease. Endocr. Rev. 19, 269-301 (1998).

55. Diorio, D., Viau, V. \& Meaney, M. J. The role of the medial prefrontal cortex (cingulate gyrus) in the regulation of hypothalamic-pituitary-adrenal responses to stress. J. Neurosci. 13, 3839-3847 (1993).

56. Chiba, S. et al. Chronic restraint stress causes anxiety- and depression-like behaviors, downregulates glucocorticoid receptor expression, and attenuates glutamate release induced by brain-derived neurotrophic factor in the prefrontal cortex. Prog. Neuropsychopharmacol. Biol. Psychiatry 39, 112-119 (2012). 
57. Willner, P. Validity, reliability and utility of the chronic mild stress model of depression: a 10-year review and evaluation. Psychopharmacology (Berl.) 134, 319-329 (1997).

58. Mineur, Y. S., Belzung, C. \& Crusio, W. E. Effects of unpredictable chronic mild stress on anxiety and depression-like behavior in mice. Behav. Brain Res. 175, 43-50 (2006).

59. Silverman, M. N. \& Sternberg, E. M. Glucocorticoid regulation of inflammation and its behavioral and metabolic correlates: from HPA axis to glucocorticoid receptor dysfunction. Ann. N. Y. Acad. Sci. 1261, 55-63 (2012).

60. Steptoe, A. \& Whitehead, D. L. Depression, stress, and coronary heart disease: the need for more complex models. Heart 91, 419-420 (2005).

61. Surwit, R. S., Schneider, M. S. \& Feinglos, M. N. Stress and Diabetes Mellitus. Dia Care 15, 1413-1422 (1992).

62. Rosmond, R. Role of stress in the pathogenesis of the metabolic syndrome. Psychoneuroendocrinology 30, 1-10 (2005).

63. Björntorp, P. et al. Adipose tissue fat cell size and number in relation to metabolism in randomly selected middle-aged men and women. Metabolism. 20, 927-935 (1971).

64. DeFronzo, R. A. et al. The Effect of Insulin on the Disposal of Intravenous Glucose: Results from Indirect Calorimetry and Hepatic and Femoral Venous Catheterization. Diabetes 30, 1000-1007 (1981).

65. Yuen, K. C. J., Chong, L. E. \& Riddle, M. C. Influence of glucocorticoids and growth hormone on insulin sensitivity in humans. Diabet. Med. 30, 651-663 (2013).

66. Henriksen, J. E., Alford, F., Vaag, A., Handberg, A. \& Beck-Nielsen, H. Intracellular skeletal muscle glucose metabolism is differentially altered by dexamethasone treatment of normoglycemic relatives of type 2 diabetic patients. Metabolism 48, 1128-1135 (1999).

67. Schakman, O., Kalista, S., Barbé, C., Loumaye, A. \& Thissen, J. P. Glucocorticoid-induced skeletal muscle atrophy. Int. J. Biochem. Cell Biol. 45, 2163-2172 (2013).

68. Dardevet, D. et al. Sensitivity and protein turnover response to glucocorticoids are different in skeletal muscle from adult and old rats. Lack of regulation of the ubiquitin-proteasome proteolytic pathway in aging. J. Clin. Invest. 96, 2113-2119 (1995).

69. Glickman, M. H. \& Ciechanover, A. The Ubiquitin-Proteasome Proteolytic Pathway: Destruction for the Sake of Construction. Physiol. Rev. 82, 373-428 (2002).

70. Mitch, W. E. \& Goldberg, A. L. Mechanisms of disease: Mechanisms of muscle wasting: The role of the ubiquitin-proteasome pathway. N. Engl. J. Med. 335, 1897-1905 (1996).

71. Clarke, B. A. et al. The E3 Ligase MuRF1 Degrades Myosin Heavy Chain Protein in Dexamethasone-Treated Skeletal Muscle. Cell Metab. 6, 376-385 (2007).

72. Neel, B. A., Lin, Y. \& Pessin, J. E. Skeletal muscle autophagy: a new metabolic regulator. Trends Endocrinol. Metab. 24, 635-643 (2013).

73. Lum, J. J., DeBerardinis, R. J. \& Thompson, C. B. Autophagy in metazoans: cell survival in the land of plenty. Nat. Rev. Mol. Cell Biol. 6, 439-448 (2005).

74. Masiero, E. et al. Autophagy Is Required to Maintain Muscle Mass. Cell Metab. 10, 507-515 (2009).

75. Yamamoto, D. et al. Branched-chain amino acids protect against dexamethasone-induced soleus muscle atrophy in rats. Muscle Nerve 41, 819-827 (2010).

76. Lützner, N., Kalbacher, H., Krones-Herzig, A. \& Rösl, F. FOXO3 Is a Glucocorticoid Receptor Target and Regulates LKB1 and Its Own Expression Based on Cellular AMP Levels via a Positive Autoregulatory Loop. PLoS ONE 7, e42166 (2012). 
77. English, P. J., Coughlin, S. R., Hayden, K., Malik, I. A. \& Wilding, J. P. H. Plasma adiponectin increases postprandially in obese, but not in lean, subjects. Obes. Res. 11, 839844 (2003).

78. Grodsky, G. M., Curry, D., Landahl, H. \& Bennett, L. [Further studies on the dynamic aspects of insulin release in vitro with evidence for a two-compartmental storage system]. Acta Diabetol. Lat. 6 Suppl 1, 554-578 (1969).

79. Perreault, L., Bergman, B. C., Hunerdosse, D. M., Playdon, M. C. \& Eckel, R. H. Inflexibility in Intramuscular Triglyceride Fractional Synthesis Distinguishes Prediabetes From Obesity in Humans. Obes. Silver Spring Md 18, 1524-1531 (2010).

80. Kahn, S. E., Hull, R. L. \& Utzschneider, K. M. Mechanisms linking obesity to insulin resistance and type 2 diabetes. Nature 444, 840-846 (2006).

81. Kahn, S. E. The Importance of $\beta$-Cell Failure in the Development and Progression of Type 2 Diabetes. J. Clin. Endocrinol. Metab. 86, 4047-4058 (2001).

82. Rafacho, A., Roma, L. P., Taboga, S. R., Boschero, A. C. \& Bosqueiro, J. R. Dexamethasone-induced insulin resistance is associated with increased connexin $36 \mathrm{mRNA}$ and protein expression in pancreatic rat islets. Can. J. Physiol. Pharmacol. 85, 536-545 (2007).

83. Jeong, I. K. et al. The effects of dexamethasone on insulin release and biosynthesis are dependent on the dose and duration of treatment. Diabetes Res. Clin. Pract. 51, 163-171 (2001).

84. Gremlich, S., Roduit, R. \& Thorens, B. Dexamethasone Induces Posttranslational Degradation of GLUT2 and Inhibition of Insulin Secretion in Isolated Pancreatic $\beta$ Cells COMPARISON WITH THE EFFECTS OF FATTY ACIDS. J. Biol. Chem. 272, 3216-3222 (1997).

85. Ogawa, A. et al. Roles of insulin resistance and beta-cell dysfunction in dexamethasoneinduced diabetes. J. Clin. Invest. 90, 497-504 (1992).

86. Bates, H. E. et al. Adaptation to intermittent stress promotes maintenance of $\beta$-cell compensation: comparison with food restriction. Am. J. Physiol. - Endocrinol. Metab. 295, E947-E958 (2008).

87. Király, M. A. et al. Attenuation of type 2 diabetes mellitus in the male Zucker diabetic fatty rat: the effects of stress and non-volitional exercise. Metabolism 56, 732-744 (2007).

88. Goodyear, PhD, L. J. \& Kahn, MD, B. B. Exercise, Glucose Transport, and Insulin Sensitivity. Annu. Rev. Med. 49, 235-261 (1998).

89. Zierath, J. R. Invited Review: Exercise training-induced changes in insulin signaling in skeletal muscle. J. Appl. Physiol. 93, 773-781 (2002).

90. Dela, F., von Linstow, M. E., Mikines, K. J. \& Galbo, H. Physical training may enhance $\beta$ cell function in type 2 diabetes. Am. J. Physiol. - Endocrinol. Metab. 287, E1024-E1031 (2004).

91. Park, S., Hong, S. M., Lee, J. E. \& Sung, S. R. Exercise improves glucose homeostasis that has been impaired by a high-fat diet by potentiating pancreatic beta-cell function and mass through IRS2 in diabetic rats. J. Appl. Physiol. Bethesda Md 1985 103, 1764-1771 (2007).

92. Tsuchiya, M. et al. Chronic exercise enhances insulin secretion ability of pancreatic islets without change in insulin content in non-diabetic rats. Biochem. Biophys. Res. Commun. 430, 676-682 (2013).

93. Oliveira, C. A. M. de et al. Exercise at anaerobic threshold intensity and insulin secretion by isolated pancreatic islets of rats. Islets 2, 240-246 (2010). 
94. Schiaffino, S. \& Mammucari, C. Regulation of skeletal muscle growth by the IGF1-Akt/PKB pathway: insights from genetic models. Skelet. Muscle 1, 4 (2011).

95. Davies, C. T. \& Few, J. D. Effects of exercise on adrenocortical function. J. Appl. Physiol. 35, 887-891 (1973).

96. GRAY, I. \& BEETHAM, W. P., Jr. Changes in plasma concentration of epinephrine and norepinephrine with muscular work. Proc. Soc. Exp. Biol. Med. Soc. Exp. Biol. Med. New York N 96, 636-638 (1957).

97. Stults-Kolehmainen, M. A. The interplay between stress and physical activity in the prevention and treatment of cardiovascular disease. Front. Clin. Transl. Physiol. 4, 346 (2013).

98. Salmon, P. Effects of physical exercise on anxiety, depression, and sensitivity to stress: A unifying theory. Clin. Psychol. Rev. 21, 33-61 (2001).

99. Martins, L. C. X. \& Lopes, C. S. Rank, job stress, psychological distress and physical activity among military personnel. BMC Public Health 13, 716 (2013).

100. Castilla-Ortega, E. et al. Voluntary exercise followed by chronic stress strikingly increases mature adult-born hippocampal neurons and prevents stress-induced deficits in 'what-when-where' memory. Neurobiol. Learn. Mem. 109, 62-73 (2014).

101. Laybutt, D. R. et al. Critical Reduction in $\beta$-Cell Mass Results in Two Distinct Outcomes over Time ADAPTATION WITH IMPAIRED GLUCOSE TOLERANCE OR

DECOMPENSATED DIABETES. J. Biol. Chem. 278, 2997-3005 (2003).

102. Rohleder, N. Acute and chronic stress induced changes in sensitivity of peripheral inflammatory pathways to the signals of multiple stress systems - 2011 Curt Richter Award Winner. Psychoneuroendocrinology 37, 307-316 (2012).

103. Ayroldi, E. et al. Mechanisms of the anti-inflammatory effects of glucocorticoids: genomic and nongenomic interference with MAPK signaling pathways. FASEB J. Off. Publ. Fed. Am. Soc. Exp. Biol. 26, 4805-4820 (2012).

104. Barnes, P. J. Anti-inflammatory actions of glucocorticoids: molecular mechanisms. Clin. Sci. Lond. Engl. 1979 94, 557-572 (1998).

105. Becker, D. E. Basic and Clinical Pharmacology of Glucocorticosteroids. Anesth. Prog. 60, 25-32 (2013).

106. Pratt, W. B. Steroid Receptor Interactions with Heat Shock Protein and Immunophilin Chaperones. Endocr. Rev. 18, 306-360 (1997).

107. McKay, L. I. \& Cidlowski, J. A. Molecular Control of Immune/Inflammatory Responses: Interactions Between Nuclear Factor- $\kappa \mathrm{B}$ and Steroid Receptor-Signaling Pathways. Endocr. Rev. 20, 435-459 (1999).

108. Sapolsky, R. M., Romero, L. M. \& Munck, A. U. How Do Glucocorticoids Influence Stress Responses? Integrating Permissive, Suppressive, Stimulatory, and Preparative Actions. Endocr. Rev. 21, 55-89 (2000).

109. Radomski, M. W., Palmer, R. M. \& Moncada, S. Glucocorticoids inhibit the expression of an inducible, but not the constitutive, nitric oxide synthase in vascular endothelial cells. Proc. Natl. Acad. Sci. U. S. A. 87, 10043-10047 (1990).

110. Pluss, C., Werner, E. R., Wachter, H. \& Pfeilschifter, J. Differential effect of dexamethasone on interleukin $1 \beta$ - and cyclic AMP-triggered expression of GTP cyclohydrolase I in rat renal mesangial cells. Br. J. Pharmacol. 122, 534-538 (1997). 
111. $\mathrm{Wu}, \mathrm{C}$. C. et al. Lipocortin 1 mediates the inhibition by dexamethasone of the induction by endotoxin of nitric oxide synthase in the rat. Proc. Natl. Acad. Sci. U. S. A. 92, 34733477 (1995).

112. Freo, U., Holloway, H. W., Kalogeras, K., Rapoport, S. I. \& Soncrant, T. T. Adrenalectomy or metyrapone-pretreatment abolishes cerebral metabolic responses to the serotonin agonist 1-(2,5-dimethoxy-4-iodophenyl)-2-aminopropane (DOI) in the hippocampus. Brain Res. 586, 256-264 (1992).

113. Doyle, P., Rohner-Jeanrenaud, F. \& Jeanrenaud, B. Local cerebral glucose utilization in brains of lean and genetically obese (fa/fa) rats. Am. J. Physiol. 264, E29-36 (1993).

114. Dallman, M. F. et al. Feast and famine: critical role of glucocorticoids with insulin in daily energy flow. Front. Neuroendocrinol. 14, 303-347 (1993). 


\section{CHAPTER 3. STUDY DESIGN AND METHODS}

$40 \mathrm{Male}$ Balb/c mice were randomized into 4 groups; sedentary ( $\mathrm{N}=10$ : Sed), sedentary stressed $(\mathrm{N}=10$ : SedSt), exercise ( $\mathrm{N}=10$ : $\mathrm{EX})$, and exercise stressed ( $\mathrm{N}=10$ : $\mathrm{EXSt}) .20$ mice were given free access to running wheels over 4 weeks after which, 10 were randomized to $7 \mathrm{hrs} / \mathrm{d}, 5 \mathrm{~d} / \mathrm{wk}$. of stress for 8 wks. 20 mice remained sedentary with no access to running wheels; after 4 weeks 10 of these mice were randomized to $7 \mathrm{hrs} / \mathrm{d}, 5 \mathrm{~d} / \mathrm{wk}$. of stress for $8 \mathrm{wks}$. The varying stressors included bath ( $1.5 \mathrm{~cm}$ water in bottom of cage), damp bedding, no bedding, cage tilt, altered light cycles, and cage-switching. Exercise mice were given access to running wheels from approximately $3: 30$ p.m. to 7:30 a.m., primarily during the dark cycle. Exercise mice were also given access to running wheels during the weekends. Immediately after the $8^{\text {th }}$ week mice were euthanized in $\mathrm{CO}^{2}$ chamber. Tissues were then excised and snap frozen in isopentane and placed into liquid nitrogen until stored at $-80^{\circ} \mathrm{C}$. Immunohistochemistry staining of $\beta$ cells in pancreatic sections were obtained using an insulin antibody to determine the number of $\beta$ cells per islets and islet area. Muscle wet weight, real time PCR, and western blotting were used to quantify the effects of exercise and CMS on muscle size, atrophy gene expression, total AKT, phosphorylated AKT and autophagy protein expression respectively, in the gastrocnemius, plantaris, and soleus muscles.

\section{METHODS}

\section{Immunohistochemisty and Imaging}

Pancreases were quickly excised from euthanized animals and immediately placed onto $2 \mathrm{~cm} \times 2$ $\mathrm{cm}$ cork blocks and imbedded using tissue embedding medium (O.C.T. Tissue Tek) then quickly dipped into isopentane for 10 seconds and lastly placed into liquid nitrogen. Samples were stored at $-80^{\circ} \mathrm{C}$ until sectioning on cryostat. Sections were cut at $7 \mu \mathrm{m}$ thickness with $25 \mu \mathrm{m}$ in between 
each section from the same animal. Tissue sections were traced with a Pap pen. Pap pen tracings were allowed 10 minutes to dry before the sections were rehydrated in PBS. Sections were fixed to slides by $4 \%$ paraformaldehyde in PBS, and the slides were subsequently washed in PBS for 3 x 5 minutes. Permeabilization was in $200 \mathrm{mg}$ sodium citrate in $200 \mathrm{ml}$ distilled water and $200 \mu \mathrm{l}$ Triton X-100 for 3 minutes at $4^{\circ} \mathrm{C}$. This was followed by another $3 \times 5$ minute wash in PBS. Goat serum (Vecta Shield) was used to block sections for 20 minutes at room temperature. Primary anti-rabbit Insulin antibody (Sigma) at 1:300 concentrations in PBS was incubated overnight at $4^{\circ} \mathrm{C}$. Primary antibodies were washed off by PBS $3 \times 10$ minutes. A secondary antibody, Alexa Fluor 546 goat anti rabbit (Invitrogen) at a 1:1000 concentration in PBS was applied to slides and incubated at room temperature for 45 minutes. Following the secondary antibodies the sections were washed in PBS 3 x 10 minutes. Hard set DAPI (Vecta shield) was used to stain cell nuclei and keep cover slip in place. Imaging was done using the Nikon E800 (Nikon) microscope fitted with RT spot imaging camera (Diagnostic Instruments). Images were viewed on computer monitor and taken as single images of the illuminated Alexa Fluor 546 or DAPI and merged using Spot Advanced imaging software package (Diagnostic Instruments).

\section{Islet morphology and Beta Cell counting}

Approximately 200 islets from each group were analyzed and $\beta$ cells counted individually from each islet using Image $\mathrm{J}$. Image $\mathrm{J}$ was also used to determine the area of each islet in arbitrary units and normalized to total pancreatic section area. The islets were categorized for each group by average size; grouping small, medium, and large islets. Average numbers of $\beta$ cells per islet area were calculated for each group.

\section{Western Blot Analysis}

Whole muscle samples of the gastrocnemius were homogenized using a lysis buffer. Coomassie 
(Bradford) protein assay was conducted to acquire the protein concentrations for loading samples prior to gel electrophoresis. Loading samples were generated for Western Blot at $75 \mu \mathrm{g} / \mu \mathrm{L} .30 \mu \mathrm{L}$ of loading samples were subjected to gel electrophoresis in 4-12\% bis-tris (NuPage) gel at 200 volts. The gel was then transferred to a nitrocellulose membrane at $4^{\circ} \mathrm{C}$ for $2: 20$ hours at $170 \mathrm{~mA}$ in transfer buffer. The membranes were cut into strips at the molecular weights corresponding to MuRF1, MAFbx, ATG-7, ATG-12, Beclin-1, AKT, pAKT and GAPDH. Strips were subsequently blocked in $2 \%$ non-fat dry milk blocking solution for 1 hour prior to incubating overnight with gentle rocking at $4^{\circ} \mathrm{C}$ in primary antibodies for MuRF1, MAFbx, ATG-7, ATG12, Beclin-1, AKT, pAKT and GAPDH. Following overnight incubation, membranes were washed 3x in TBST for 5 minutes each. After washing, secondary anti-rabbit HRP linked antibodies (1:1000) were applied to the membrane and incubated at room temperature for 1 hour. Membranes were then washed 4 times for 15 minutes in TBST prior to applying ECL and imaged using the GBOX (Syngene).

\section{Real Time PCR}

RNA was extracted from $1 / 5$ of the mid-belly of the gastrocnemius muscle using $500 \mathrm{uL}$ of TRIzol reagent and a hand held homogenizer. Homogenate was incubated for 10 minutes at room temperature then $140 \mathrm{uL}$ of chloroform was added, then vortexed and centrifuged at $4^{\circ} \mathrm{C}$ for 15 minutes 12000 RCF. Supernatatant was removed and placed in $1.5 \mathrm{ml}$ RNAse free tube. RNeasy kit (Quiagen) was used for the remaining steps of the RNA extraction. Digestion of DNA was done by adding $0.1 \mathrm{x}$ vol. RNA to $1 \mu 1$ of DNAse I -incubated at $37^{\circ} \mathrm{C}$ for 30 minutes, then adding $0.1 \mathrm{x}$ vol DNase inactivation reagent and incubated at room temp for 2 minutes. The mixture was centrifuged for 90 seconds at $10000 \mathrm{RCF}$. One microgram of total RNA was then reverse transcribed using Superscript Vilo according to the manufacturers protocols (Invitrogen). PCRs were performed by using SensiFAST SYBER HI-ROX (Bioline) kit according to the 
manufacturer's instructions. The following primer sets were used in PCRs: murf-1, zfand5, atrogin-1, fbxo3, bard1, ube2d1, ubez2, ube4a, fbx120, torpors, nedd41. GAPDH primers were used as a sample normalizer. 260/280 values were quantified using Nano Drop. RT-qPCRs were performed on an Mx 3005p Real Time PCR system (Stratagene). The temperature cycle profile for the qPCR reactions was $95{ }^{\circ} \mathrm{C}$ for $15 \mathrm{~min}$ and 40 cycles of $94{ }^{\circ} \mathrm{C}$ for $15 \mathrm{~s}, 55^{\circ} \mathrm{C}$ for $30 \mathrm{~s}$, and $72{ }^{\circ} \mathrm{C}$ for $30 \mathrm{~s}$. Melting curve analysis was also included at one cycle of $95^{\circ} \mathrm{C}$ for $1 \mathrm{~min}, 55^{\circ} \mathrm{C}$ for $30 \mathrm{~s}$, and $95^{\circ} \mathrm{C}$ for $30 \mathrm{~s}$ to verify the specificity of the amplified PCR products. The amount of amplified transcripts (2 CT) was estimated by the comparative CT method and normalized to an endogenous reference (GAPDH) relative to a calibrator. All PCR products were verified on agarose gel stained with ethidium bromide to discriminate between the correct amplification products and the potential primer dimers.

\section{Statistical Analysis}

All data are represented as a mean $\pm \mathrm{SE}$, with a criterion of $P<.05$ and were assessed using one -way and two-way ANOVAs as a means of statistical significance. Individual differences were evaluated using Tukey's HSD post hoc test (GraphPad Prism 4.0 software) with adjustments made for multiple comparisons. 


\section{CHAPTER 4. RESULTS}

\section{Body Weights}

The body weights of the stressed mice were not significantly different from that of the control mice over the entirety of the 8 week study (Figure 1). The exercise stressed mice had significantly increased body weights when compared to the exercise only mice with the significant differences not occurring until 4 weeks into the stress period (indicated on graph by black box). (Exercise $25.75 \mathrm{~g} \pm 1.08$; Exercise Stress $27.28 \mathrm{~g} \pm 1.16$ ) These two groups remained significantly different from week 8 until the end of the study (Figure $1 . P<.05$ ) Exercise only mice also had significantly decreased body weights compared to the sedentary mice at week 11 and at the end of the study (Figure $1 . P<.05$ ). Additionally at the end of the study the exercise only mice had a significantly decreased body weight compared with the stressed mice (Figure 1. $P<.05)$.

\section{Distance and Time spent running}

The exercise stressed mice spent significantly less time running and ran an average of $3.2 \mathrm{~km}$ over the course of the 8 week stress period, as compared to the distance run by the exercise only mice which averaged $4.4 \mathrm{~km}$ (Figure $2 . P<.05)$. Additionally, the exercise stressed mice spent less time running compared to the exercise only mice (Exercise Stressed 157 minutes; Exercise 212 minutes; Figure 2. $P<.05)$.

\section{Muscle Morphometrics}

Muscle wet weight was used to determine if stress or exercise or the combination of the two would result in any significant changes in the mass of the hindlimb muscles; specifically the gastrocnemius, soleus, and plantaris. Muscle wet weights (mg) were normalized to body weight (g). Significant differences occurred between the Exercise mice and the Sedentary mice with the exercise mice showing an $11.43 \%$ increase in the wet weight of the gastrocnemius muscle and an 
$18.84 \%$ increase in the wet weight of the plantaris (Figure $3, P<.05$ ). The plantaris weight of the Exercise only mice also was increased compared to the Sedentary Stressed mice (Figure 3, $P<$ $.05)$. Additionally the Exercise Stressed mice had significant increases of the normalized gastrocnemius wet weight (13\% and 15\%) and plantaris wet weight (29\% and 24\%) compared to the Sedentary and Sedentary Stressed mice, respectively (Figure 3, $P<.05$ ). No significant differences were seen in the weight of the soleus between any of the groups. Absolute muscle weights of the gastrocnemius and the plantaris were only increased in the Exercise Stressed group (Table 1). There was no absolute muscle wet weight difference between the Sedentary, Sedentary Stressed, and Exercise mice when examined for gastrocnemius, plantaris, and soleus. However, the Exercise Stressed mice had increased absolute muscle wet weight of the gastrocnemius when compared to Sedentary, Stressed, and Exercise only mice. (Table 1, $P<$ $.05)$.

\section{Mean $\beta$ cell number per islet}

The mean number of $\beta$ cells per islet was examined by counting individual DAPI stained $\beta$ cells within the insulin stained positive area. Compared to the Sedentary mice both the Stressed and Exercise Stressed mice had a higher mean number of $\beta$ cells per islet (Sedentary, $70.73 \pm 4.77$; Stressed $90.99 \pm 5.22$; Exercise Stressed $93.21 \pm 5.69$, Figure 4. $P<.05)$. The Stressed and Exercise Stressed mice also had a higher mean number of $\beta$ cells when compared to the Exercise only mice (Exercise $68.64 \pm 3.73$; Stressed $90.99 \pm 5.22$; Exercise Stressed $93.21 \pm 5.69$, Figure 4. $P<.05)$.

\section{Mean Islet area}

Islet morphology was investigated by insulin positive staining. The insulin positive area in the Exercise Stress increased 29.05\% when compared to their Exercise alone counterparts (Figure 5, $P<.05)$. The Sedentary Stressed mice had an increased islet area compared to the Exercise only 
mice, however this increase was not significant (Stressed 22445.92 \pm 1488.67; Exercise $18770.16 \pm 1187.19$; Figure 5, $P=.14)$. Representative images of the islets from each group stained with insulin (red) and DAPI (blue) can be seen in figure 6.

\section{Muscle Specific atrophy gene expression}

The relative gene expression of the muscle specific atrophy genes was not significantly different between any of the groups for either Murf-1 of Mafbx (Figure 7).

\section{Ubiquitin Proteolysis gene expression}

Ubiquitin proteolysis relative mRNA expression was significantly different between multiple groups for the genes Nedd41 and Topors. Topors relative expression levels were significantly reduced in the Exercise and Exercise Stressed groups compared to both the Sedentary and Sedentary Stressed mice (Figure $8 . P<.05$ ). Nedd41 realtive mRNA expression was significantly reduced in the Exercise mice when compared to both the Sedentary and Sedentary Stressed mice (Figure 8. $P<.05$ ). Interestingly, the Exercise Stress mice had increased levels of Nedd41 mRNA expression when compared to the Exercise mice (Figure 8. $P<.01$ ).

\section{E3 Ubiquitin Ligase protein abundance}

Maf-bx protein expression levels were not consistently expressed clearly and reliably thus there was no quantification available aside from the mRNA data. MURF-1 protein abundance was not significantly different between any of the groups (Figure 9).

\section{Autophagy protein abundance}

Autophagy was measured by the proteins Beclin-1, ATG-7, LC3a isoform and LC3b isoform.

Beclin-1 was significantly reduced in the Exercise Stressed group when compared to the Sedentary mice (Figure 10. A, $P<.05$ ). ATG-7 remained unchanged across all groups (Figure 
10. B). The LC3a isoform was unchanged across all groups (Figure 10. C). The LC3b isoform was significantly increased in the Exercise Stressed mice when compared with the Sedentary mice (Figure 10. D, $P<.05$ ).

\section{Mouse Coat States}

Although the coat states of the mice were not consistently quantified, observations on a subset of mice indicated that the stressed mice had deteriorating coat conditions over the course of the 8 week study. Additionally stressed mice were visibly more agitated and aggressive when being handled as compared to the sedentary non-stressed mice.

\section{Total AKT and pAKT protein abundance}

Following the discovery that the muscle had not undergone atrophy in the Exercise Stressed mice and the wet weights were actually increased, the total AKT and pAKT protein levels were examined by western blotting to further elucidate a cause for the increased muscle weight. Both the total AKT and the pAKT protein abundance levels were significantly increased in the Exercise Stressed mice when compared to the Sedentary mice (Figure $11 \mathrm{~A} \& \mathrm{~B}, P<.05$ ).

\section{CHAPTER 5. DISCUSSION}

The central aim of this thesis was to determine the effects of chronic stress alone and in combination with exercise on murine $\beta$ cell morphology and skeletal muscle atrophy gene expression, ubiquitin proteolysis gene expression, and protein markers of autophagy expression. The central hypothesis was that a CMS protocol of 8 weeks would result in the expansion of the $\beta$ cells resulting in an increased insulin positive area and additionally would result in the atrophy of the hind limb skeletal muscle through up-regulation of skeletal muscle specific atrophy genes Murf-1 and Mafbx along with up-regulation of ubiquitin proteolysis genes. The introduction of 
voluntary wheel running in combination with CMS was hypothesized to result in the attenuation of $\beta$ cell expansion and the attenuation of skeletal muscle atrophy as measured by the normalized wet weight of the muscle and atrophy gene expression. The main finding of this thesis was that CMS resulted in a significant increase in $\beta$ cells per islet and mean insulin positive area with or without exercise. Furthermore, 8 weeks of CMS did not result in muscle atrophy, but in fact resulted in significant increases in normalized muscle wet weight when compared to Sedentary mice. The use of CMS in combination with voluntary wheel running is unique and these findings are novel.

Initially we set out to determine if there was any $\beta$ cell loss in the Islets of Langerhans due to increased apoptosis as indicated by TUNEL staining. Butler et al. reported that human T2DM patients showed a decreased $\beta$ cell mass due to apoptosis ${ }^{3}$. However, our findings demonstrated that 8 weeks of CMS was not a great enough insult or long enough to result in a loss of $\beta$ cell mass through increased $\beta$ cell apoptosis (observational data).

The life cycle of $\beta$ cells in patients with T2DM has been elegantly summarized by Weir and Bonner-Weir ${ }^{15}$. We believe that the level of stress used in the present study resulted in what Weir and Bonner-Weir term as stage 1 and stage 2 of the progression of $\beta$ cell dysfunction. Stage 1 is defined as the compensation phase with expansion of the islet cells and the stable adaptation of these cells. Stage 2 is the completion of this expanded state ${ }^{15}$. Our data support this in that the chronically stressed mice showed an increased insulin positive islet area and an increased number of $\beta$ cells per islet (Figure $4 \& 5$ ). This finding is similar to that of Kiraly et al. in which ZDF rats were intermittently stressed, resulting in $\beta$ cell expansion ${ }^{6}$. The ZDF rats in the study that were not stressed had decreased islet areas and decreased numbers of $\beta$ cells per islet ${ }^{6}$. As mentioned previously, there was no significant increase in the level of $\beta$ cell apoptosis in our 
Stressed mice when compared to the Sedentary controls. Therefore, it would appear that the Stressed mice had not reached the decompensation phase of $\beta$ cell dysfunction resulting in $\beta$ cell loss.

The insulin positive area for the Exercise group was unchanged from that of the Sedentary mice (Figure 5). However, when mice were stressed and also voluntarily exercised over an 8 week time period, the insulin positive area expanded significantly to levels greater than that of the Stressed only mice. Exercise has been shown to produce a higher insulin content of islets and higher glucose stimulated insulin secretion in isolated rodent islets ${ }^{9}$. Our data show that the combined effect of stress and exercise resulted in an insulin positive area expansion and an increase in the number of $\beta$ cell per islet (Figures $4 \& 5$ ). This expansion can be seen as a healthy response in the exercise stressed mice as the system adapts to an increase in the amount of circulating glucocorticoids and glucose; which has been shown to occur independently with exercise and stress ${ }^{11}$. Hyperglycemia can be prevented by increasing the number of $\beta$ cells and thus having more insulin available for release. Similarly with stress alone, the islet expansion during the 8 weeks of stress cannot be viewed as a maladaptation ${ }^{2}$. Although we did not measure blood glucose or corticosterone, the islet expansion observed in the stressed mice provides speculative evidence that the corticosterone levels were elevated and caused the expanded insulin positive area and increased $\beta$ cells per islet. Increased $\beta$ cell number and area has been previously demonstrated in rats following 24 days of dexamethasone administration ${ }^{8}$. Fewer than $20 \%$ of these animals became diabetic and rats that were able to maintain healthy blood glucose levels did so by increased insulin secretion ${ }^{8}$. Our results mirror this $\beta$ cell expansion and we speculate that our animals were able to maintain euglycemia through expansion of the islets and an increase in $\beta$ cell number. 
CMS had no effect on the muscle wet weights of the stressed mice. There were no significant differences between Stressed and Sedentary mice for muscle weight normalized to body weight or absolute muscle weight (Figure 3 and Table 1). This is contrary to much of the literature in which exogenous glucocorticoids either injected or delivered via subcutaneous osmotic mini pump resulted in muscle proteolysis ${ }^{10,14}$. The atrophy previously observed could be the result of the synthetic glucocorticoid dexamethasone, which has a much higher affinity for the glucocorticoid receptor when compared to natural corticosterone. However, to our knowledge no literature has analyzed muscle from a mouse subjected to a CMS protocol. According to our data the stress resulted in a change in insulin positive area of the pancreas, but did not cause skeletal muscle atrophy (Figure 3). A possible explanation could be that the CMS protocol used in the present study was insufficient to cause the necessary increase in circulating glucocorticoids that result in muscle atrophy. The levels of circulating glucocorticoids may not have reached sufficient levels to block protein synthesis and upregulate protein catbolism ${ }^{11,14}$. Another possibility could be that islet expansion and increased insulin availability prevented skeletal muscle protein degradation and therefore overall muscle atrophy. Insulin has been shown to have an anti-catabolic effect when administered in vitro to myocytes and L8 myoblasts ${ }^{4}$. Additionally insulin injection has been shown to antagonize the effects of glucocorticoids on myofibrillar protein balance in rats ${ }^{13}$. The increases in insulin positive area and the glucocorticoids ineffectiveness to cause atrophy in the hindlimb muscle, may have been the result of an insulin to corticosterone ratio that was anti-catabolic or even anabolic for the muscle (Figure 3). The increase in insulin availability combined with voluntary exercise appeared to result in a protective effect of the muscle, leading to a greater wet weight. Muscle specific atrophy gene expression was not affected by either stress or exercise. 
These results are consistent with the previous explanation that either the stress protocol was not sufficient enough, the mice had become habituated to the stress, or that circulating insulin was high enough to prevent the anti-anabolic or catabolic action of glucocorticoids ${ }^{12}$. The mRNA relative expression levels of the atrogenes MuRF-1 and MAFbx were not significantly increased in the Stressed mice and were unchanged across all groups (Figure 7). However, genes involved in the ubiquitin proteasome pathway were significantly decreased in the Exercise mice (Figure 8). Reduced expression levels of Topors and Nedd41 when compared to Sedentary and Stressed mice demonstrated that the Exercise only mice possibly had decreased protein degradation occurring within their skeletal muscle. However, Nedd 41 did show an increased relative expression in the Exercise Stressed mice when compared to Exercise mice. This may indicate that exercise alone was able to reduce the level of protein degradation as measured by this gene but was unable to do so when the animals were stressed. The mice that underwent CMS alone had no change in these protein degradation pathway genes which leads us to believe that the stress was not great enough to result in muscle atrophy.

The relative protein abundance of the atrogenes was similar with the mRNA data in that no significant changes occurred between the groups (Figure 9). We had a difficult time with the MAFbx antibody and getting it to reliably show up on the blots, therefore the data were excluded. (Supplemental Figure 2)

Skeletal muscle autophagy, measured by Beclin-1, ATG-7 and LC3a/b protein abundance, indicated an increased level of autophagy for the Exercise Stressed mice when compared to the Sedentary mice based upon the significant increase in the LC3b isoform, which is a final effector in autophagosome formation ${ }^{72}$ (Figure 10D). However, the abundance of Beclin-1, which initiates autophagy through complexation with various autophagy proteins (Atg14, Vps15, 
UVRAG, Rubicon, class III PI3K) was significantly increased in the Sedentary mice when compared to the Exercise Stressed mice (Figure 10 A). A possible explanation could have to do with the amount of time elapsed from the last bout of exercise to sacrifice. Kim et al. found that muscle abundance of Beclin-1 protein was significantly decreased immediately post exercise when compared with sedentary controls ${ }^{5}$. The Exercise Stressed mice, which had access to running wheels, could have exercised right up until the time of sacrifice. This could be a possible explanation as to why we saw the significant decrease in Beclin-1 protein in the Exercise Stressed group. Additionally this explanation comes into play when evaluating the protein abundance of the LC3a isoform and LC3b isoforms. The LC3a isoform was unchanged across all groups; however the LC3b isoform, which when increased, is indicative of complete phagophore formation, was significantly increased in the Exercise Stressed mice (Figure $10 \mathrm{D}$ ). The last bout of exercise may have occurred within hours of sacrifice which could have caused the increased level of the LC3b isoform. Kim et al. also examined the LC $3 \mathrm{a} / \mathrm{b}$ isoforms following exercise and concluded that protein abundance of the LC3a isoform is reduced when compared to nonexercising controls immediately following exercise ${ }^{5}$. However, when Kim et al examined the LC3b isoform, it was non-significantly increased in the mice that were sacrificed immediately following exercise when compared to controls ${ }^{5}$. Our data showed that the combination of exercise and stress caused an elevation in the protein abundance of the LC3b isoform while having no effect on the protein abundance of the LC3A isoform (Figure $10 \mathrm{C} \& \mathrm{D}$ ).

Body weights were not significantly different between the Sedentary and the Sedentary Stressed mice; however significance did occur between the Exercise and Exercise Stressed mice, with the latter having a greater body mass after 4 weeks of stress (Figure 1). Previous studies have demonstrated that a chronic stress protocol can result in a depressed like state in mice and a 
decreased body weight after just 4 weeks of chronic stress ${ }^{13}$. A possible explanation for the lack of weight loss observed in our stressed mice could be related to the strain of mouse used in our study. Schweizer et al. showed significant body weight differences in the stressed D2OIa mice and $\mathrm{BL} / 6 \mathrm{~J}$ mice compared to their non-stressed counterparts, with the stressed mice gaining less weight over the course of the 10 week study ${ }^{13}$. Additionally, Schweizer et al. demonstrated a sucrose preference difference between strains of mice, a key metric used in the determination of anhedonia ${ }^{13}$. Sucrose preference returned to baseline levels at the end of the study in the Balb/c $\operatorname{strain}^{13}$. Schweizer et. al demonstrated that Balb/c mice appeared to be able to adapt better to stress compared to other strains. This may be a reason why the chronic stress protocol used in the present study did not result in as many significant detrimental effects as we would have expected to see. Conversely, the enhanced insulin positive area and greater $\beta$ cell number seen in the exercise stressed mice may have led to a general anabolic state due to greater circulating insulin levels. Although speculative, this may have provided the necessary hormonal environment to cause increased growth and body weight.

Laboratory records indicated that the stressed mice demonstrated poor grooming of their coats with thin, patchy, and dirty coats. Additionally, stressed mice had red conjunctivae which is a common occurrence in mice subjected to chronic stress ${ }^{17}$. The lab notes, although not completely qualitative, provide us with some evidence of the levels of stress that the mice were experiencing. A sign that the mice were stressed was that the stressed mice did not voluntarily run as much as the mice that were not being stressed (Figure 2) (unpublished data from DeVallence et al.) Previous research has shown that when mice experience increased levels of stress, it resulted in them being less active than their non-stressed counterparts ${ }^{12}$. However, it is important to take into consideration that much like in humans, hypoactivity and hyperactivity can 
occur in depressive like states ${ }^{16}$. This has been demonstrated by Mineur et al. who used multiple strains of mice to determine the effects of $\mathrm{CMS}^{17}$. This study demonstrated that particular strains respond to CMS through hyperactivity while others respond through hypoactivity, and the method of the behavioral testing can influence activity based on the strain of the animal as well.

The total AKT and pAKT levels were examined when it was discovered that the gastrocnemius and plantaris from the Exercise Stressed mice had increased wet weight and that the atrogenes were not upregulated in the Sedentary Stressed mice. Both the total AKT and pAKT levels were increased in the Exercise Stressed mice when compared with the Sedentary Stressed mice (Figure 11A \& B). An elevated phosphorylation of AKT (Figure 11B) may indicate an increase in insulin signaling and perhaps further downstream increases in protein synthesis and inhibition of protein degradation in the gastrocnemius and plantaris of the Exercise Stressed mice ${ }^{94}$.

\section{Limitations and Future Directives}

A large limitation of this study is the lack of plasma levels of corticosterone, insulin, glucose, and glucagon. We have provided a limited glimpse into a model that we believe results in hyperinsulinemia and elevated corticosterone based on previous research ${ }^{6,9}$ and our data of $\beta$ cell expansion in number and of insulin positive area in stressed animals. A single blood sample measure of corticosterone would have provided very little information because of the large diurnal release of this hormone. Quantifying changes in circulating corticosterone is difficult and requires multiple samples taken over multiple days collected at the same time of day. Including this information would have given us an idea as to how the stress affected the diurnal nature of corticosterone release and if the levels would be comparable to that seen in mice that have demonstrated muscle atrophy with injected corticosterone or dexamethasone. Future studies 
should examine these factors to determine if exercise has a beneficial effect on plasma insulin levels and corticosterone levels when animals are subjected to chronic stress.

In order to determine a pathway for the expansion of insulin positive area and increased $\beta$ cell number per islet, $\beta$ cells of the pancreas should have been isolated from half of our animals, with the other half of the animals having their pancreas used for IHC. The glucose stimulated insulin release and the insulin content of the $\beta$ cells could have been measured in order to understand the effects of stress and/or exercise on the $\beta$ cells. Additionally the GLUT-2 receptor could have been examined through western blots of these isolated cells as it has been shown to have reduced protein expression in diabetic models where there is also a loss in $\beta$ cell function ${ }^{101}$. Although we believe our $\beta$ cells were still in the compensation phase it would have been interesting to examine the endoplasmic reticulum stress pathway as it has been implicated in $\beta$ cell death in T2DM ${ }^{1}$. These measures would have provided the study with functional measures and other pathways that could be the cause of the functional changes.

An initial aim of this thesis was to examine the $\beta$ cell to $\alpha$ cell ratio and determine if stress resulted in an increase of $\alpha$ cells as has been observed in T2DM humans ${ }^{13}$. This goal was not achieved due to the antibody for glucagon not providing a reliably accurate stain of the $\alpha$ cells. The exact cause of this poor staining is unknown, however we were using a mouse antibody on a mouse tissue and therefore the result was a large amount of non-specific binding and inconclusive results. Future studies should examine this along with the $\beta$ cell morphology to determine if there is an irregular rise in the number or area of glucagon positive $\alpha$ cells. Plasma levels of glucagon would also need to be determined in order to further elucidate the stress effects on the mouse pancreas and overall endocrine dynamics of mice faced with chronic stress. In order to determine if the muscle weight gains discussed previously were completely 
accurate, a better way to determine enhanced growth would have been to use the cross sectional area of the gastrocnemius. Muscle morphometrics could have also been determined by fiber size of laminin immunohistochemically stained muscle sections. Muscle wet weights are a crude measure of muscle size, but in the case of this study where inflammation could have played a role in the increased weight of the muscle, wet weight might not have been the greatest choice. Further examination of protein synthesis elements, which are additionally involved in insulin signaling such as mTOR, 4E-BP1, and $\mathrm{p} 70^{\mathrm{SK} 6}$ would have provided further evidence as to whether the muscle gains observed are true gains or possibly a byproduct of muscle inflammation. Additionally, the autophagy protein data at the level of the muscle should have been from muscles that were extracted with the knowledge of exactly when the last bout of exercise occurred. This would have provided the most accurate representation of the levels of autophagy which could have been occurring due to either the stress, exercise, or both.

We needed to more accurately record the daily changes in the mice coat state and provide an additional measure of behavioral patterns to determine the magnitude of stress over time. This measure would have allowed us to better understand the level of stress the animals were experiencing throughout the 12 week study. 


\section{REFERENCES}

1. Back, Sung Hoon, and Randal J. Kaufman. "Endoplasmic Reticulum Stress and Type 2 Diabetes." Annual Review of Biochemistry 81 (2012): 767-93. doi:10.1146/annurev-biochem-072909095555.

2. Beaudry, Jacqueline L., and Michael C. Riddell. "Effects of Glucocorticoids and Exercise on Pancreatic B-cell Function and Diabetes Development." Diabetes/Metabolism Research and Reviews 28, no. 7 (2012): 560-73. doi:10.1002/dmrr.2310.

3. Butler, Alexandra E, Juliette Janson, Susan Bonner-Weir, Robert Ritzel, Robert A Rizza, and Peter C Butler. "Beta-cell Deficit and Increased Beta-cell Apoptosis in Humans with Type 2 Diabetes." Diabetes 52, no. 1 (January 2003): 102-10.

4. England, B. K., J. L. Chastain, and W. E. Mitch. "Abnormalities in Protein Synthesis and Degradation Induced by Extracellular pH in BC3H1 Myocytes.” American Journal of Physiology - Cell Physiology 260, no. 2 (February 1, 1991): C277-C282.

5. Kim, Yong An, Young Sang Kim, and Wook Song. "Autophagic Response to a Single Bout of Moderate Exercise in Murine Skeletal Muscle." Journal of Physiology and Biochemistry 68, no. 2 (June 1, 2012): 229-35. doi:10.1007/s13105-011-0135-X.

6. Király, Michael A., Holly E. Bates, Jessica T. Y. Yue, Danitza Goche-Montes, Sergiu Fediuc, Edward Park, Stephen G. Matthews, Mladen Vranic, and Michael C. Riddell. "Attenuation of Type 2 Diabetes Mellitus in the Male Zucker Diabetic Fatty Rat: The Effects of Stress and Nonvolitional Exercise.” Metabolism 56, no. 6 (June 2007): 732-44.

doi:10.1016/j.metabol.2006.12.022.

7. Laybutt, D. Ross, Mariela Glandt, Gang Xu, Yu Bai Ahn, Nitin Trivedi, Susan Bonner-Weir, and Gordon C. Weir. "Critical Reduction in $\beta$-Cell Mass Results in Two Distinct Outcomes over Time ADAPTATION WITH IMPAIRED GLUCOSE TOLERANCE OR DECOMPENSATED DIABETES.” Journal of Biological Chemistry 278, no. 5 (January 31, 2003): 2997-3005. doi:10.1074/jbc.M210581200.

8. Ogawa, A, J H Johnson, M Ohneda, C T McAllister, L Inman, T Alam, and R H Unger. "Roles of Insulin Resistance and Beta-cell Dysfunction in Dexamethasone-induced Diabetes." Journal of Clinical Investigation 90, no. 2 (August 1992): 497-504.

9. Ayensu, W. K. et al. Effects of chronic mild stress on serum complement activity, saccharin preference, and corticosterone levels in Flinders lines of rats. Physiol. Behav. 57, 165-169 (1995).

10. Oliveira, Camila Aparecida Machado de, Mauricio Ferreira Paiva, Clécia Alencar Soares Mota, Carla Ribeiro, José Alexandre Curiacos de Almeida Leme, Eliete Luciano, and Maria Alice Rostom de Mello. "Exercise at Anaerobic Threshold Intensity and Insulin Secretion by Isolated Pancreatic Islets of Rats." Islets 2, no. 4 (July 1, 2010): 240-46. doi:10.4161/isl.2.4.12266.

11. Peckett, Ashley J., David C. Wright, and Michael C. Riddell. "The Effects of Glucocorticoids on Adipose Tissue Lipid Metabolism.” Metabolism 60, no. 11 (November 2011): 1500-1510. doi:10.1016/j.metabol.2011.06.012.

12. Schakman, O., S. Kalista, C. Barbé, A. Loumaye, and J.P. Thissen. "Glucocorticoid-induced Skeletal Muscle Atrophy." The International Journal of Biochemistry \& Cell Biology 45, no. 10 (October 2013): 2163-72. doi:10.1016/j.biocel.2013.05.036.

13. Schweizer, Martin C., Markus S. H. Henniger, and Inge Sillaber. "Chronic Mild Stress (CMS) in Mice: Of Anhedonia, 'Anomalous Anxiolysis' and Activity.” PLoS ONE 4, no. 1 (January 29, 2009): e4326. doi:10.1371/journal.pone.0004326. 
14. Tomas, F M, A J Murray, and L M Jones. "Interactive Effects of Insulin and Corticosterone on Myofibrillar Protein Turnover in Rats as Determined by N Tau-methylhistidine Excretion." Biochemical Journal 220, no. 2 (June 1, 1984): 469-79.

15. Watson, Monica L., Leslie M. Baehr, Holger M. Reichardt, Jan P. Tuckermann, Sue C. Bodine, and J. David Furlow. "A Cell-autonomous Role for the Glucocorticoid Receptor in Skeletal Muscle Atrophy Induced by Systemic Glucocorticoid Exposure." American Journal of Physiology - Endocrinology and Metabolism 302, no. 10 (May 15, 2012): E1210-E1220. doi:10.1152/ajpendo.00512.2011.

16. Weir, Gordon C., and Susan Bonner-Weir. "Five Stages of Evolving Beta-Cell Dysfunction During Progression to Diabetes." Diabetes 53, no. suppl 3 (December 1, 2004): S16-S21. doi:10.2337/diabetes.53.suppl_3.S16.

17. DSM-IV, I Diagnostic and statistical manual of mental disorders. $4^{\text {th }}$ ed. Washington D.C.: American Psychiatric Association; 2000.

18. Mineur, Y. S., Belzung, C. \& Crusio, W. E. Effects of unpredictable chronic mild stress on anxiety and depression-like behavior in mice. Behav. Brain Res. 175, $43-50$ (2006). 


\section{Figure Legends}

Figure 1. Mouse body weights in (g) over the course of the 12 week study with the stress beginning at week $4 . \mathrm{N}=10$ for each group. $* P<.05$ compared to Sedentary, $\uparrow P<.05$ compared to Sedentary Stressed, \# $P<.05$ compared to Exercise only. All data are represented as a mean $\pm \mathrm{SE}$

Figure 2. Mean run time and mean total distance run per day over the 8 week exercise period for Exercise and Exercise Stress mice. $\mathrm{N}=10$ for each group. All data are represented as a mean \pm SE. \#P<.05 compared to Exercise only

Figure 3. . Muscle wet weights of gastrocnemius, plantaris, and soleus (mg) were normalized to body weight $(\mathrm{g}) . \mathrm{N}=10$ for each group. $* P<.05$ compared to Sedentary, $\dagger P<.05$ compared to Sedentary Stressed. All data are represented as a mean $\pm \mathrm{SE}$

Table 1. Absolute muscle weight recorded in $\mathrm{mg}$ from each group for the gastrocnemius, plantaris and soleus muscles. $\mathrm{N}=10$ for each group. $* P<.05$ compared to Sedentary, $\uparrow P<.05$ compared to Sedentary Stressed, \# $P<.05$ compared to Exercise. All data are represented as a mean $\pm \mathrm{SE}$

Figure 4. $\beta$ cell number in Sedentary Stress and exercise stress mice were significantly increased compared to the Sedentary group $(P<.05)$. Sedentary Stress and Exercise Stress groups were also significantly increased compared to the exercise group $(P<.05)$. $P<.05$ 
compared to Sedentary, \# $P<.05$ compared to Exercise. Representative images can be seen in Figure 3. All data are represented as a mean $\pm \mathrm{SE}$.

Figure 5. Insulin positive area is increased when Stressed mice are allowed to voluntarily exercise at night. Area was significantly increased in Exercise Stressed mice vs Exercise only mice $(P<.05)$. $\# P<.05$ compared to Exercise. $\mathrm{N}=125-209$ islets for each group. Representative images can be seen in Figure 3. All data are represented as a mean \pm SE.

Figure 6. Representative islet images from Sedentary, Sedentary Stressed, Exercise, and Exercise Stressed mice stained for Insulin (red) DAPI (blue).

Figure 7. qPCR was used to evaluate the relative expression of muscle atrophy specific genes MuRF-1 and MAFbx. The expression levels were not significantly different among the groups. $\mathrm{N}=3$ for each group. All data are represented as a mean $\pm \mathrm{SE}$.

Figure 8. qPCR relative expression levels for ubiquitin proteolysis genes Nedd4-1 and Topors. $\mathrm{N}=3$ for each group. $* P<.05$ compared to Sedentary, $\uparrow P<.05$ compared to Sedentary Stressed, $\# P<.05$ compared to Exercise. All data are represented as a mean $\pm \mathrm{SE}$.

Figure 9. MuRF-1, muscle specific atrophy protein expression in the gastrocnemius muscle with western blot image and quantification $\mathrm{N}=10$ for each group. MuRF-1 protein levels were expressed relative to GAPDH. All data are represented as a mean \pm SE. 
Figure 10. Autophagy-related protein expression in gastrocnemius muscle with western blot image and quantification of autophagy protein for Beclin-1 N=7 for each group (A) ATG-7 N=8 for each group. (B), LC3a N=8 for each group (C) LC3b N=8 for each group (D). All autophagy related protein levels were expressed relative to GAPDH. ${ }^{*} P<.05$ compared to Sedentary. All data are represented as a mean $\pm \mathrm{SE}$

Figure 11. The total AKT protein expression of the gastrocnemius muscle from Sedentary, Stressed, Exercise, and Exercise Stressed mice (A) N=2 for each group. $\dagger P<.05$ compared to sedentary stressed. The phosphorylated AKT protein content of the gastrocnemius muscle from Sedentary, Stressed, Exercise, and Exercise Stressed mice $(\mathbf{B}) \mathrm{N}=2$ for each group. $\dagger P<.05$ compared to sedentary stressed. All data are represented as a mean $\pm \mathrm{SE}$.

\section{Supplemental Figure Legends}

Supplemental Figure 1. Relative mRNA expression of ubiquitin proteolysis associated genes. $\mathrm{N}=3$ for each group. There are no significant differences between any of the groups for all the genes measured. All data are represented as a mean $\pm \mathrm{SE}$.

Supplemental Figure 2. A representative western blot image of the MaFbx protein; the arrow is pointing to the upper faint band at $42 \mathrm{kDa}$. The lower band is that of Murf-1 at $40 \mathrm{kDa}$, which was nonspecifically bound by the Mafbx antibody.

Supplemental Figure 3. Islet size distribution in $\%$ of islets per size grouping (A.U.) N=122209 for each group. 
Figures

Figure 1.

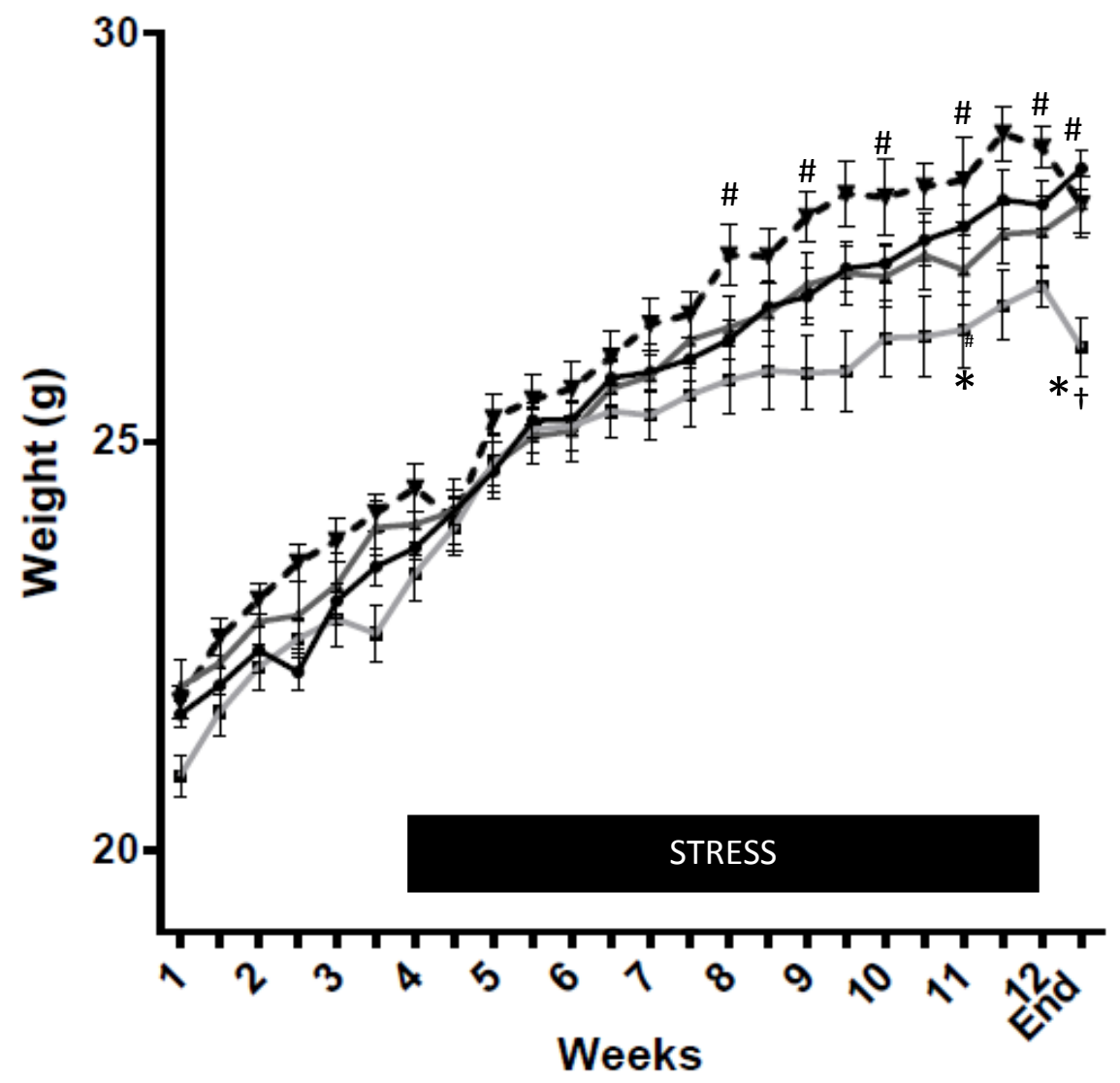

-F. Exercise Stress

- Exercise

$\rightarrow$ Sedentary Stress

- Sedentary 
Figure 2.

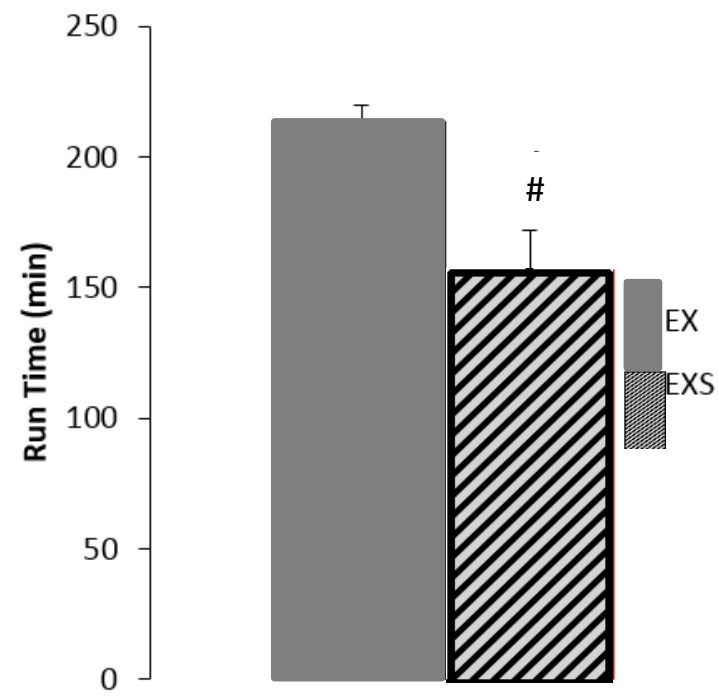

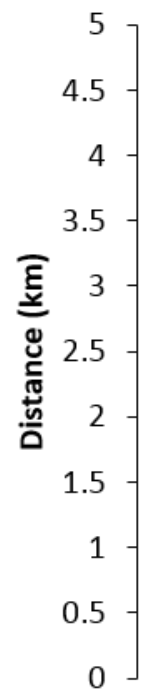

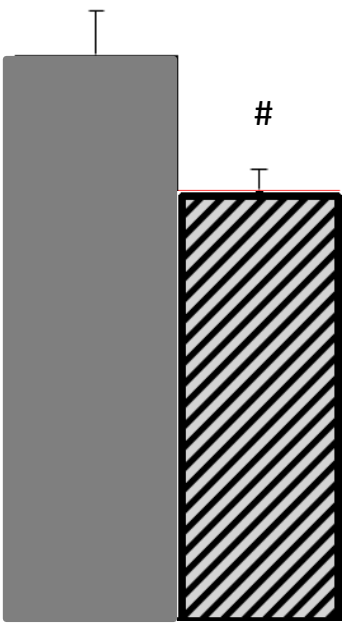


Figure 3.

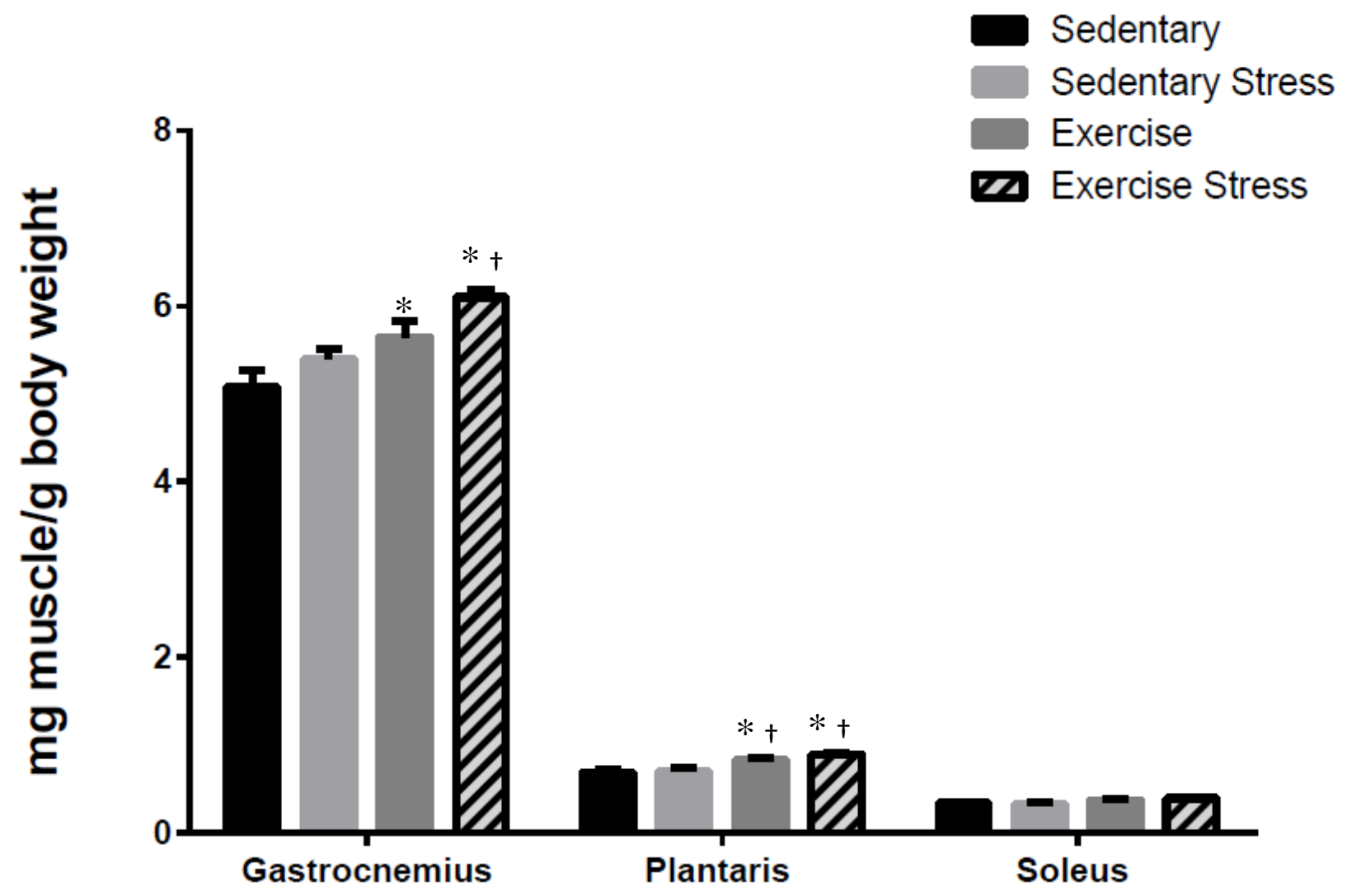


Figure 4.

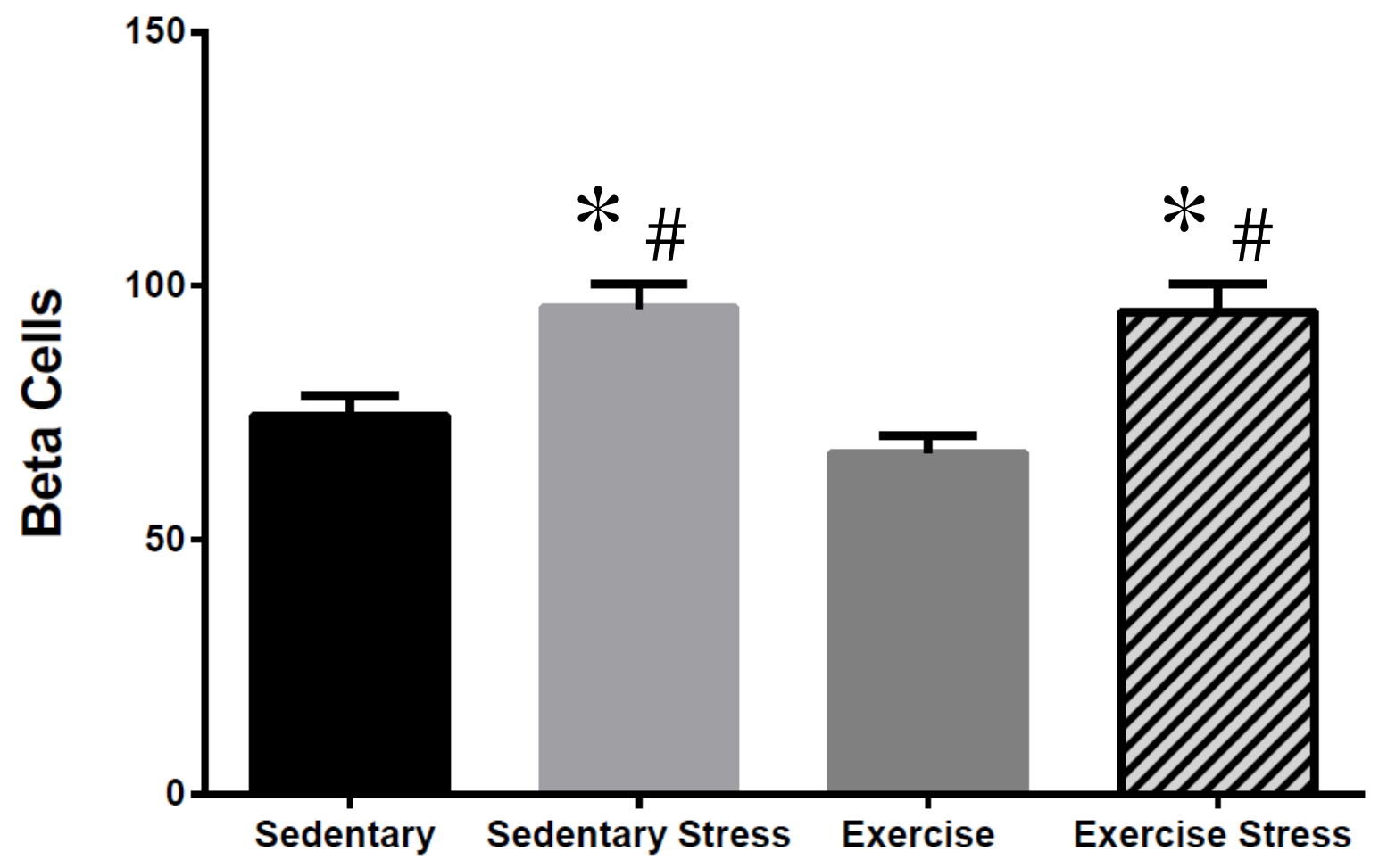


Figure 5.

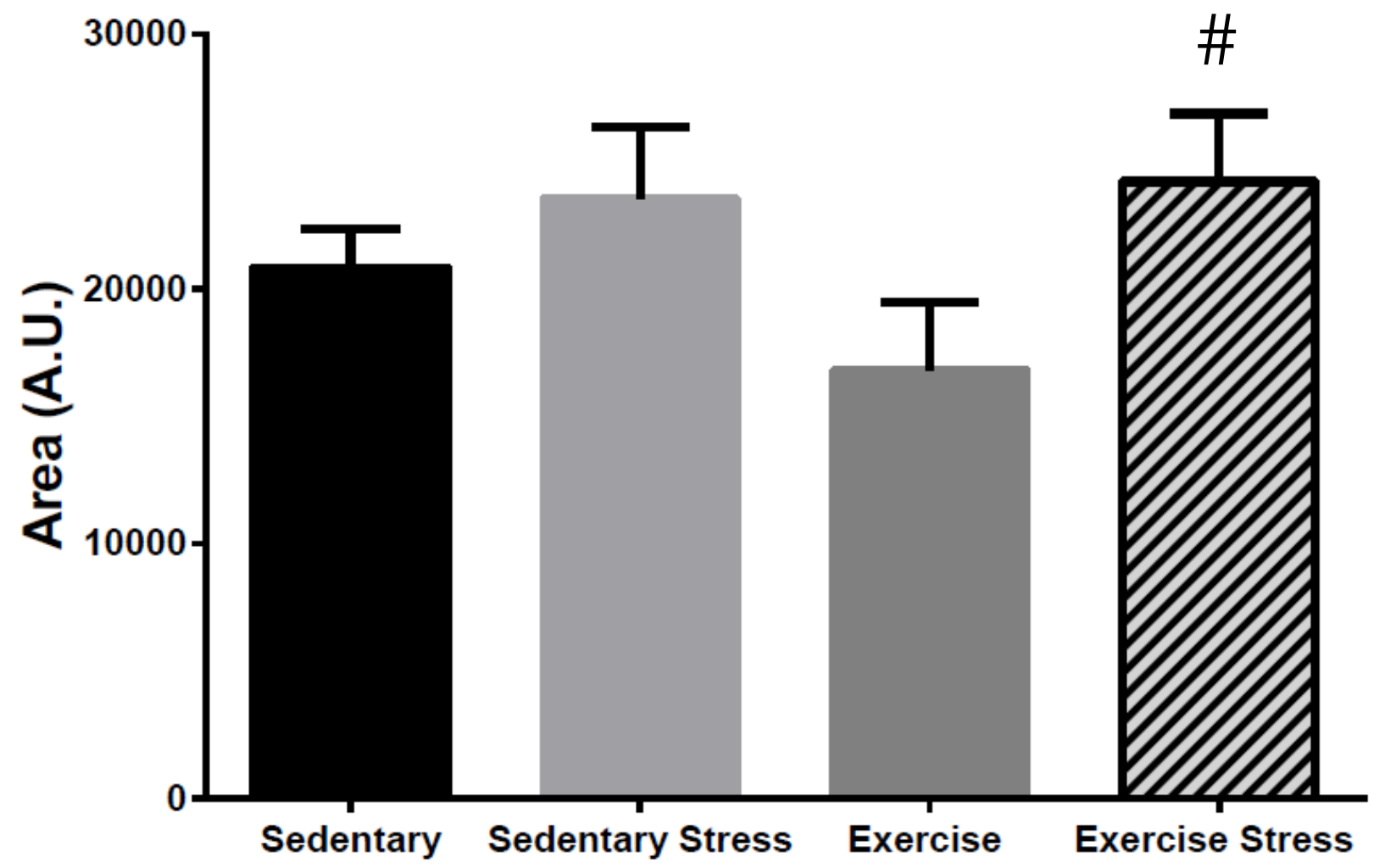


Figure 6.

Sedentary

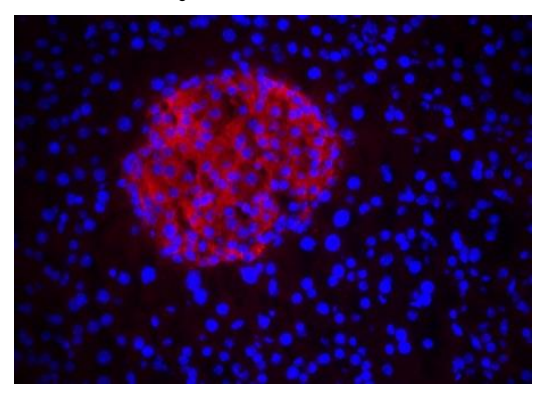

Sedentary Stress

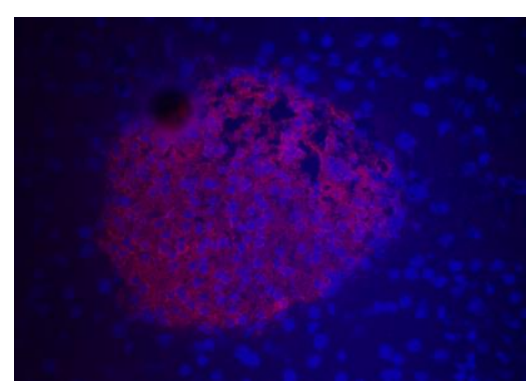

Exercise

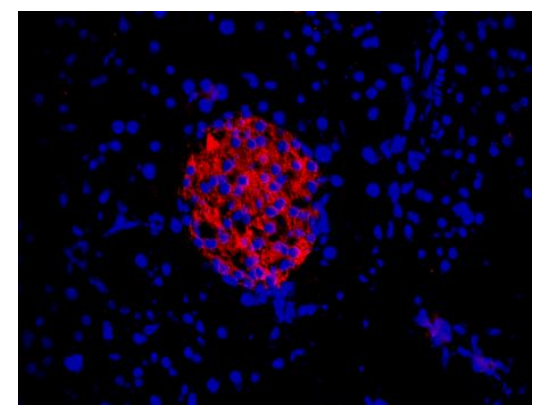

Exercise Stress

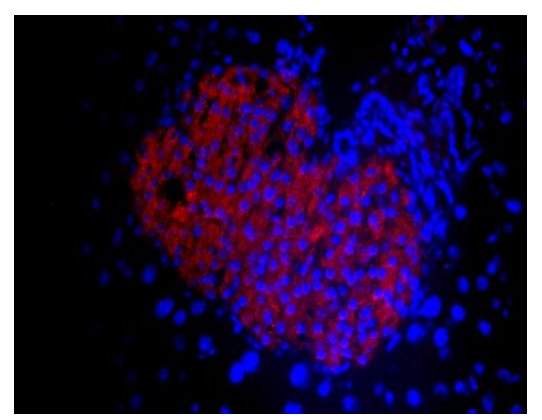


Figure 7.

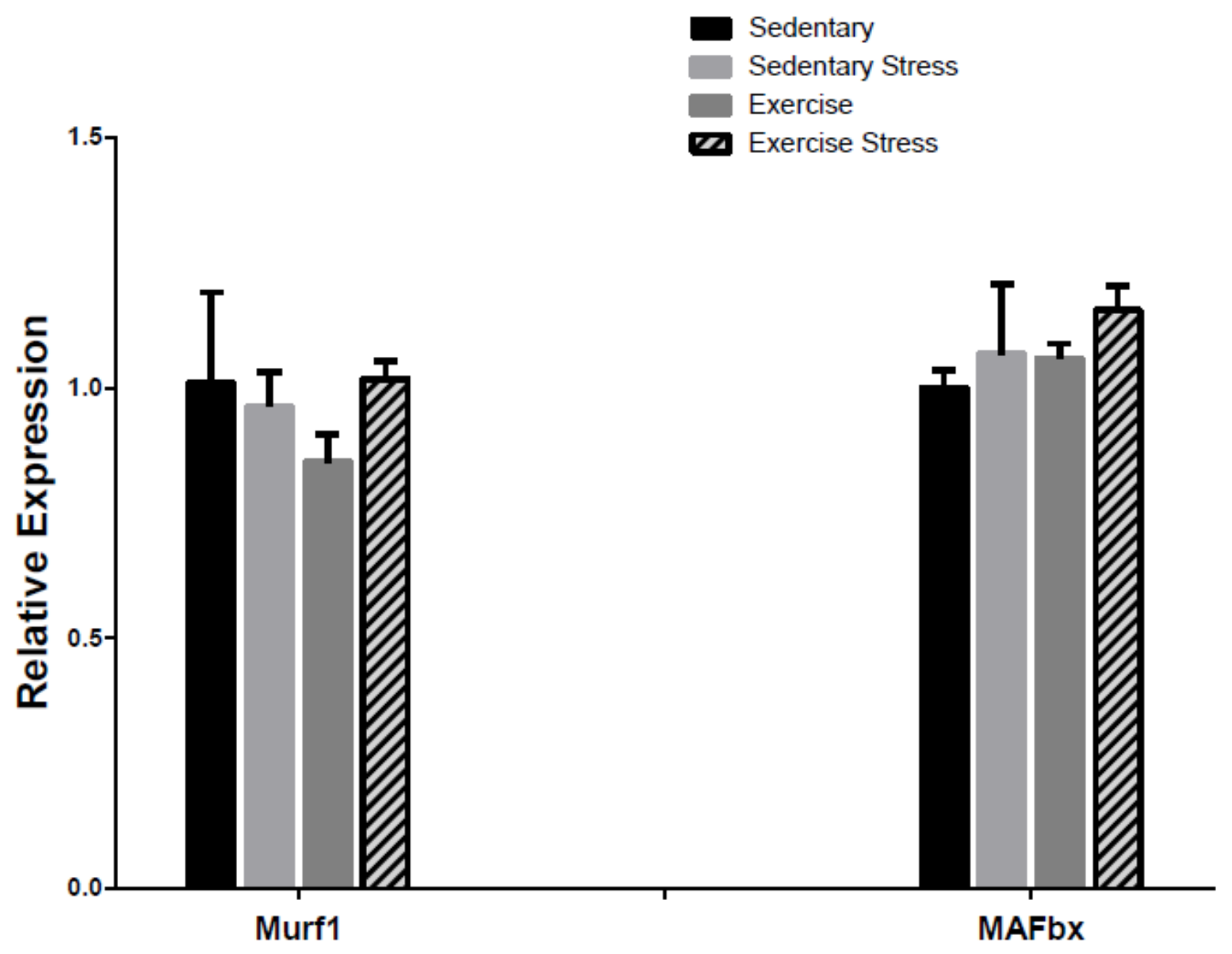

Figure 8.

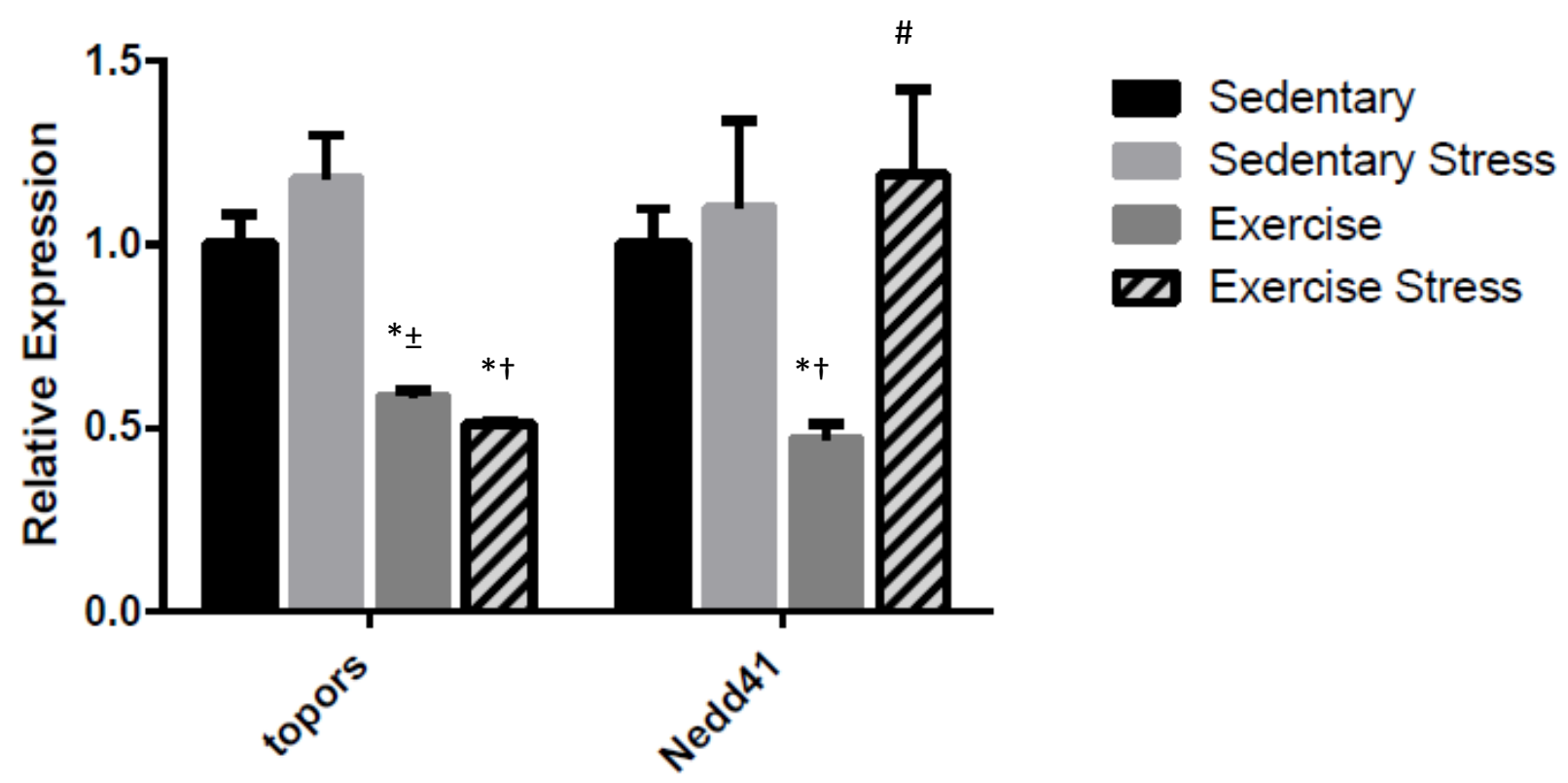


Figure 9.

Sed St Ex ExSt

MuRF1

GAPDH

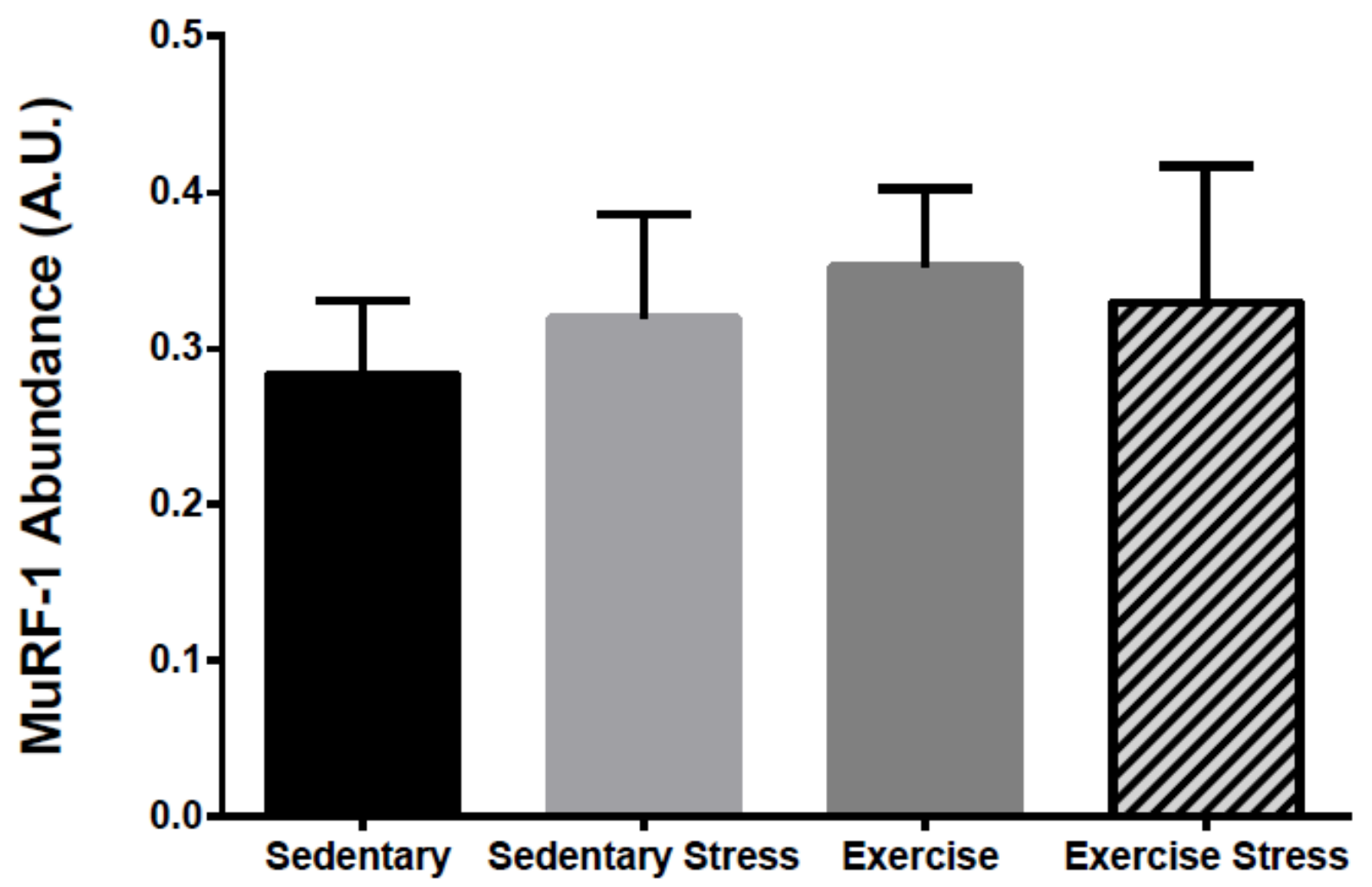


Figure $10 \mathrm{~A}$.

SedNs St Ex ExSt

Beclin-1

GAPDH

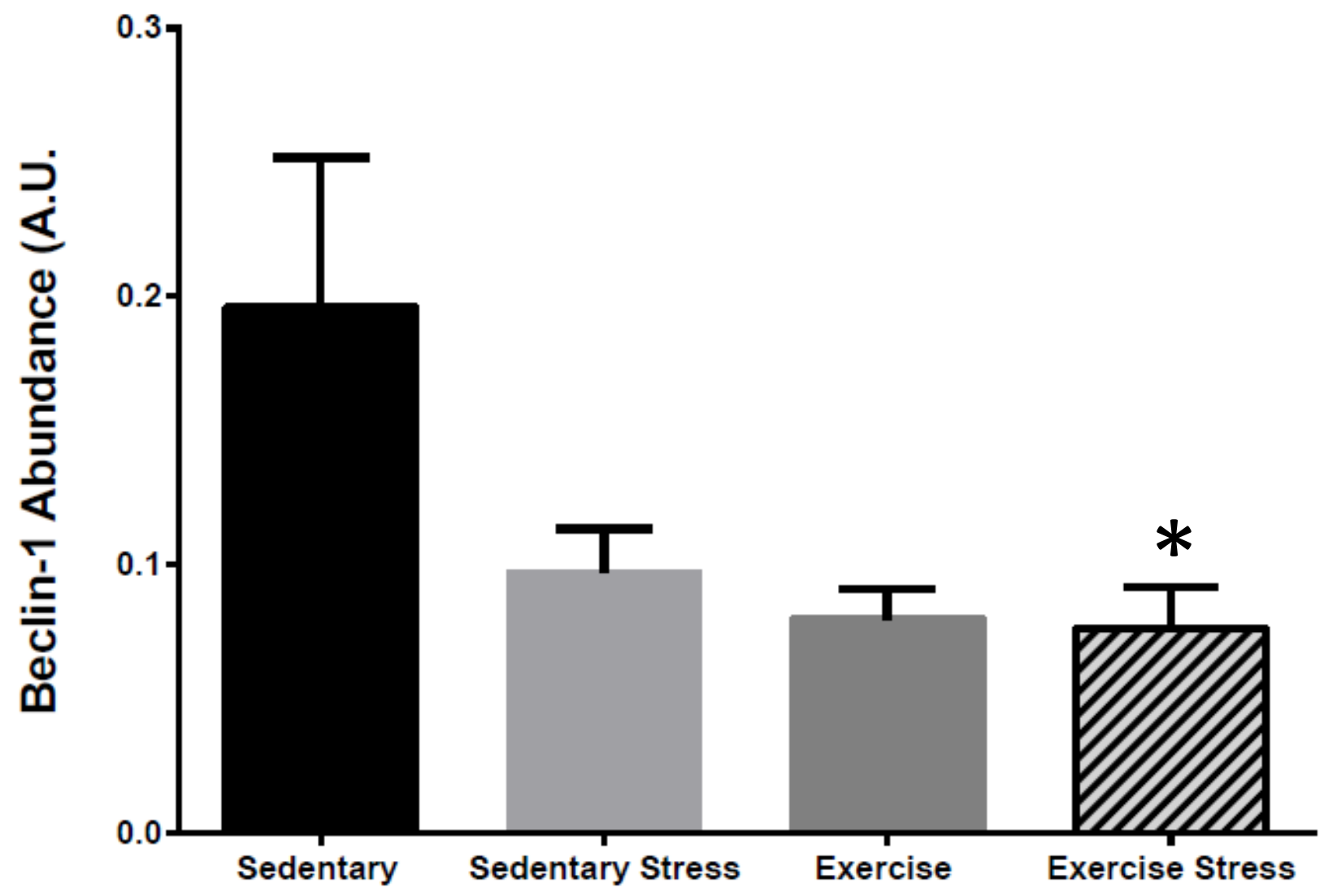


Figure 10 B.

SedNs St Ex ExSt

ATG-7

GAPDH

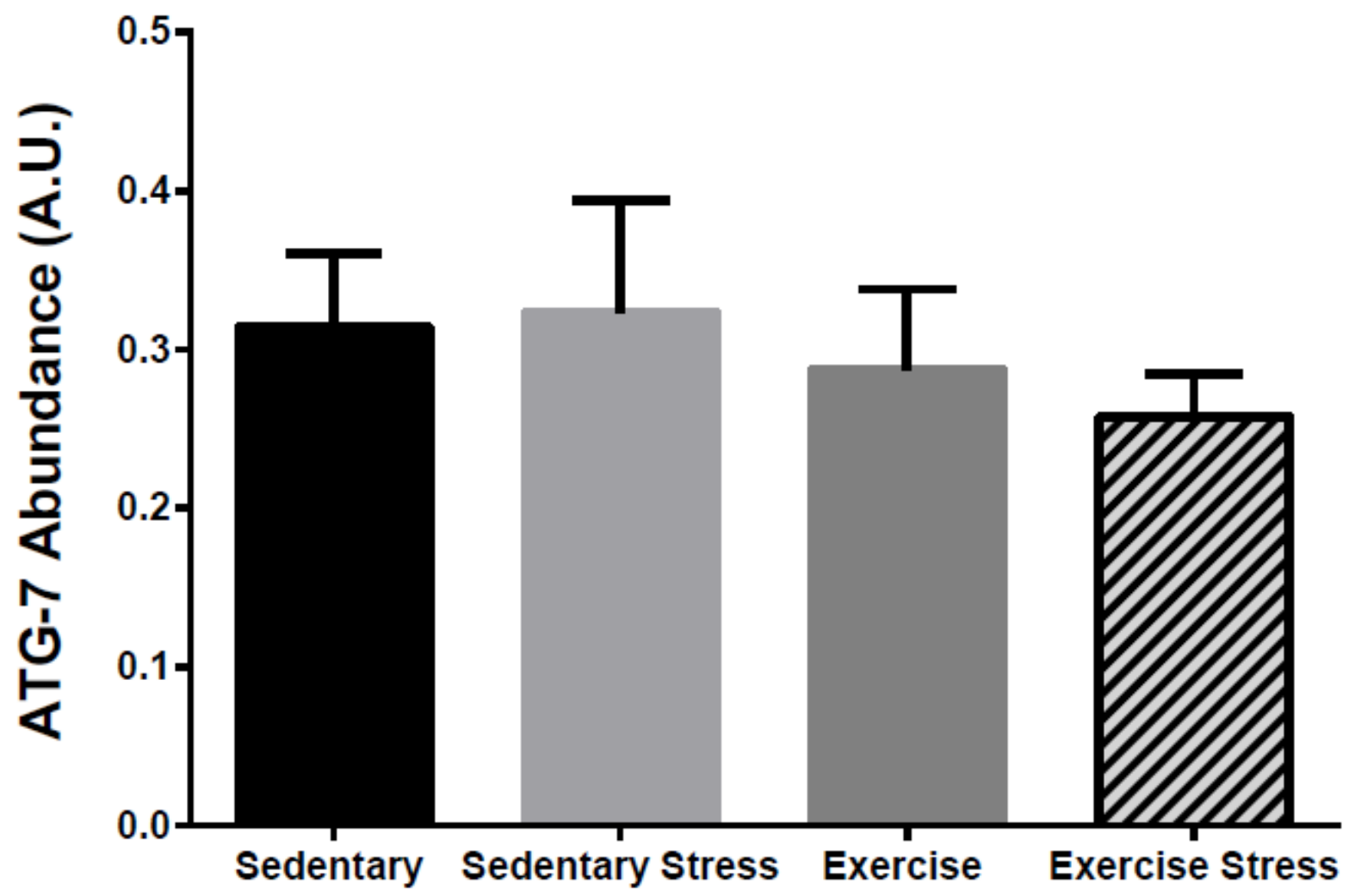


Figure $10 \mathrm{C}$.

SedNs St Ex ExSt

\section{LC3a}

GAPDH

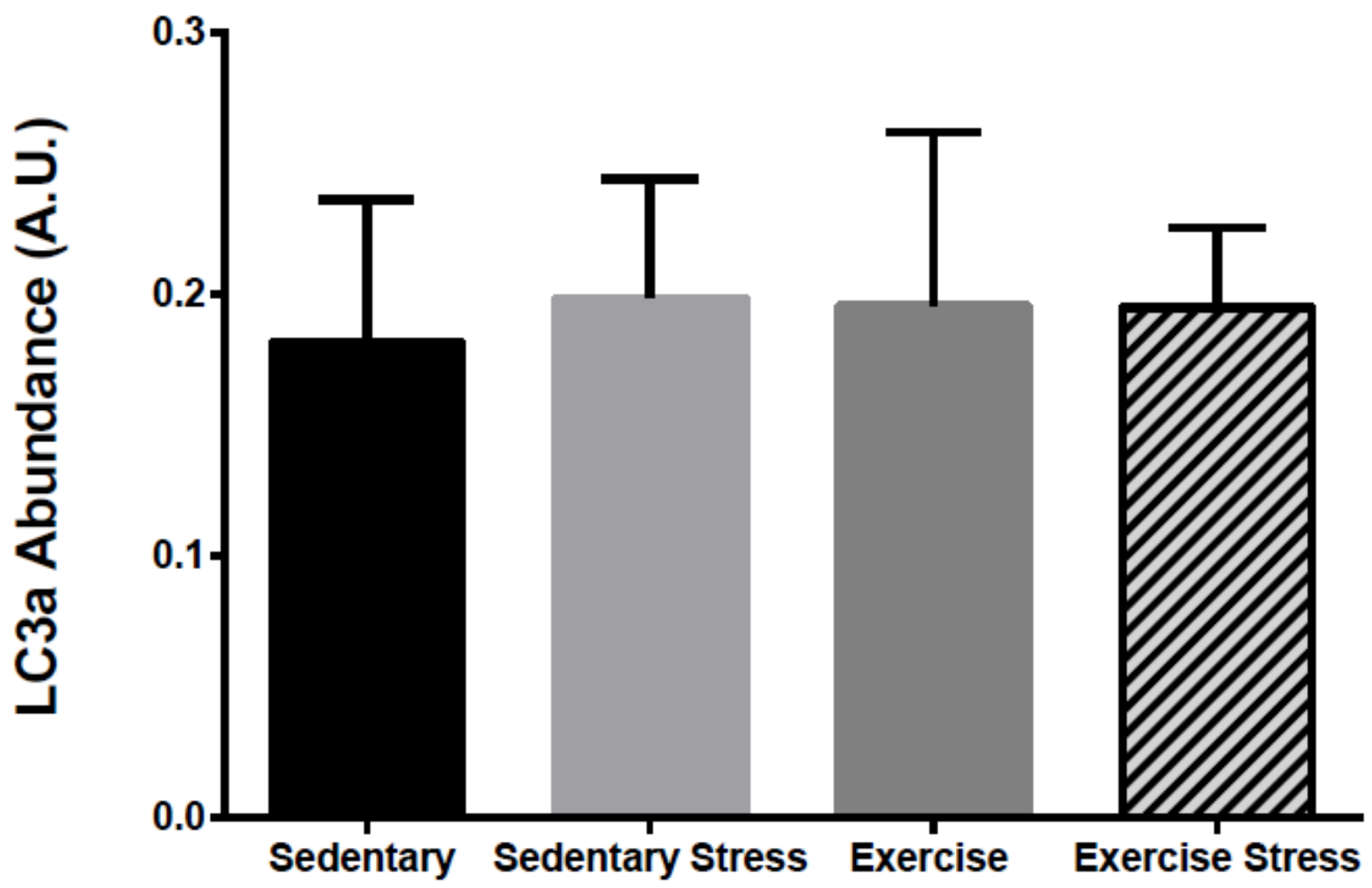


Figure 10 D.

SedNs St Ex ExSt

LC3b

GAPDH

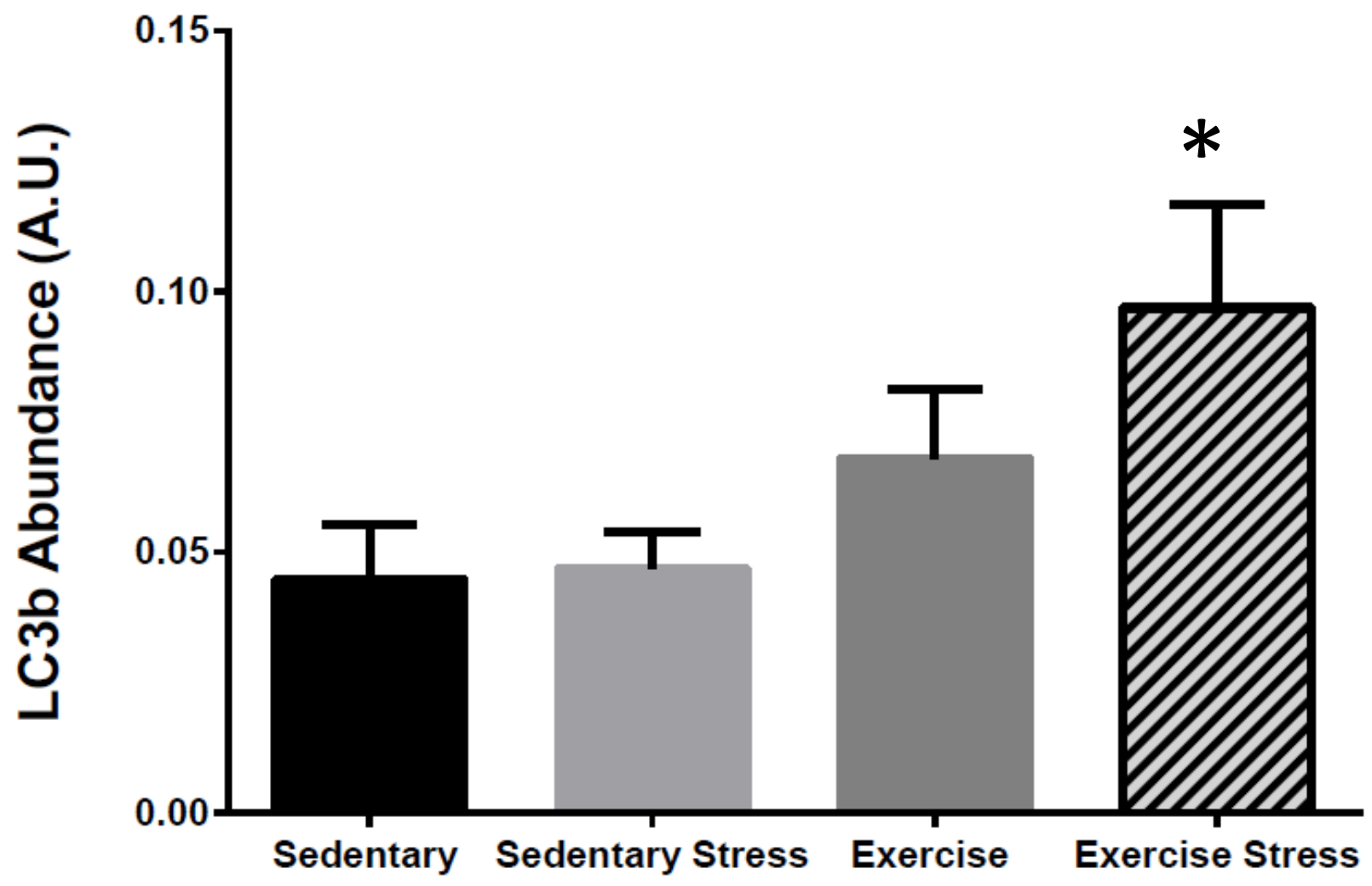


Figure 11 A.

SedNs St Ex ExSt

Total Akt

GAPDH

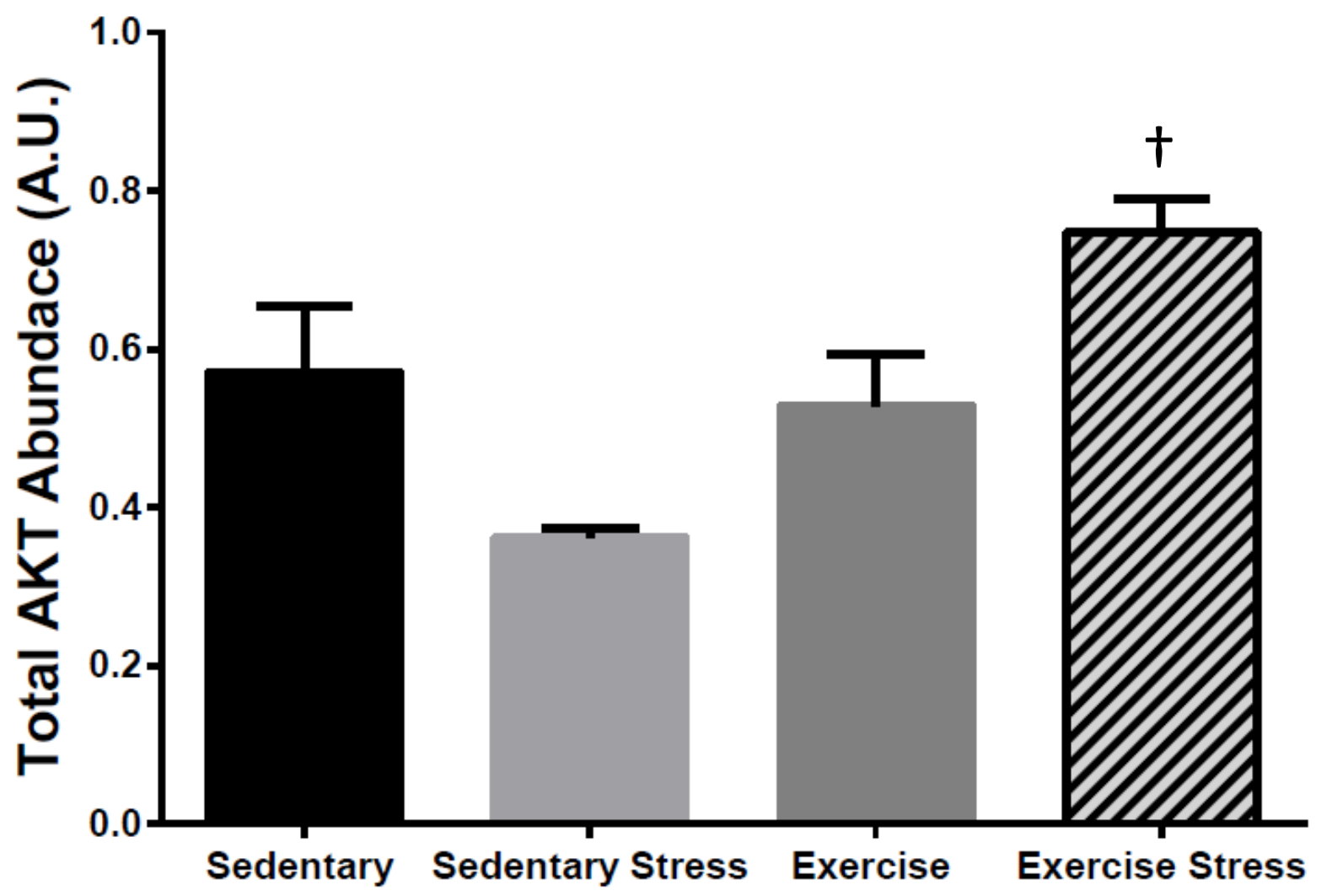


Figure 11 B

SedNs St Ex ExSt

pAKT

GAPDH
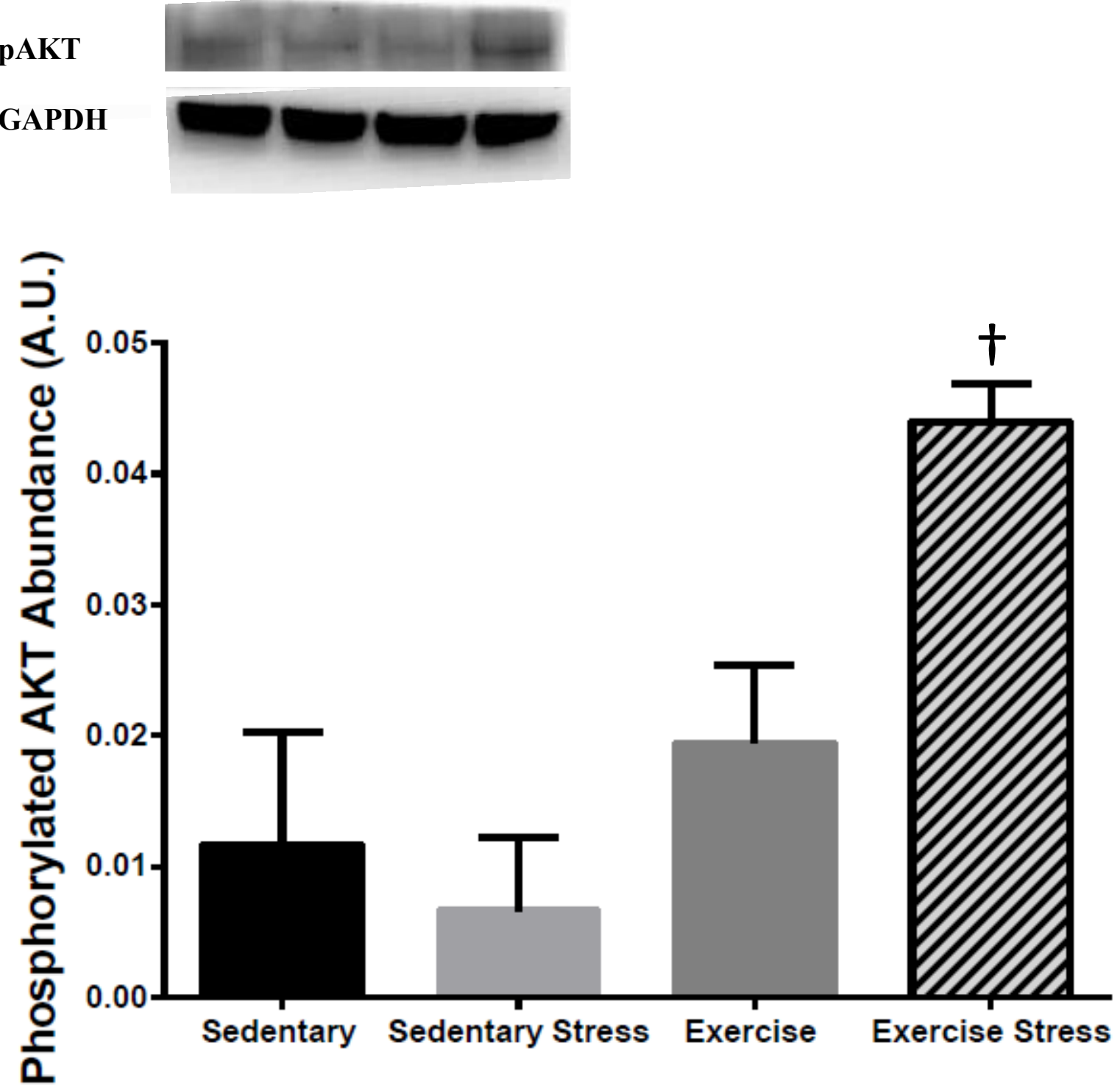
Table 1. Absolute Muscle Weights (mg)

\begin{tabular}{|l|c|c|c|c|}
\hline & Sedentary & Stress & Exercise & Exercise Stress \\
\hline Gastrocnemius & $145.81 \pm$ & $148.55 \pm$ & $148.05 \pm$ & $168.08 \pm$ \\
& 4.4127 & 3.3269 & 4.9532 & 3.0865 \\
& & & & $* \# \dagger$ \\
& & & & \\
\hline Plantaris & $19.14 \pm$ & $18.37 \pm$ & $21.37 \pm$ & $23.82 \pm$ \\
& 0.7442 & 0.6723 & 0.7987 & 0.8786 \\
& & & & \\
\hline Soleus & $9.76 \pm$ & $9.23 \pm$ & $9.93 \pm$ & $10.70 \pm$ \\
& 0.4099 & 0.6680 & 0.7142 & 0.7314 \\
& & & & \\
\hline
\end{tabular}




\section{Supplemental Figures}

\section{Supplemental Figure 1}

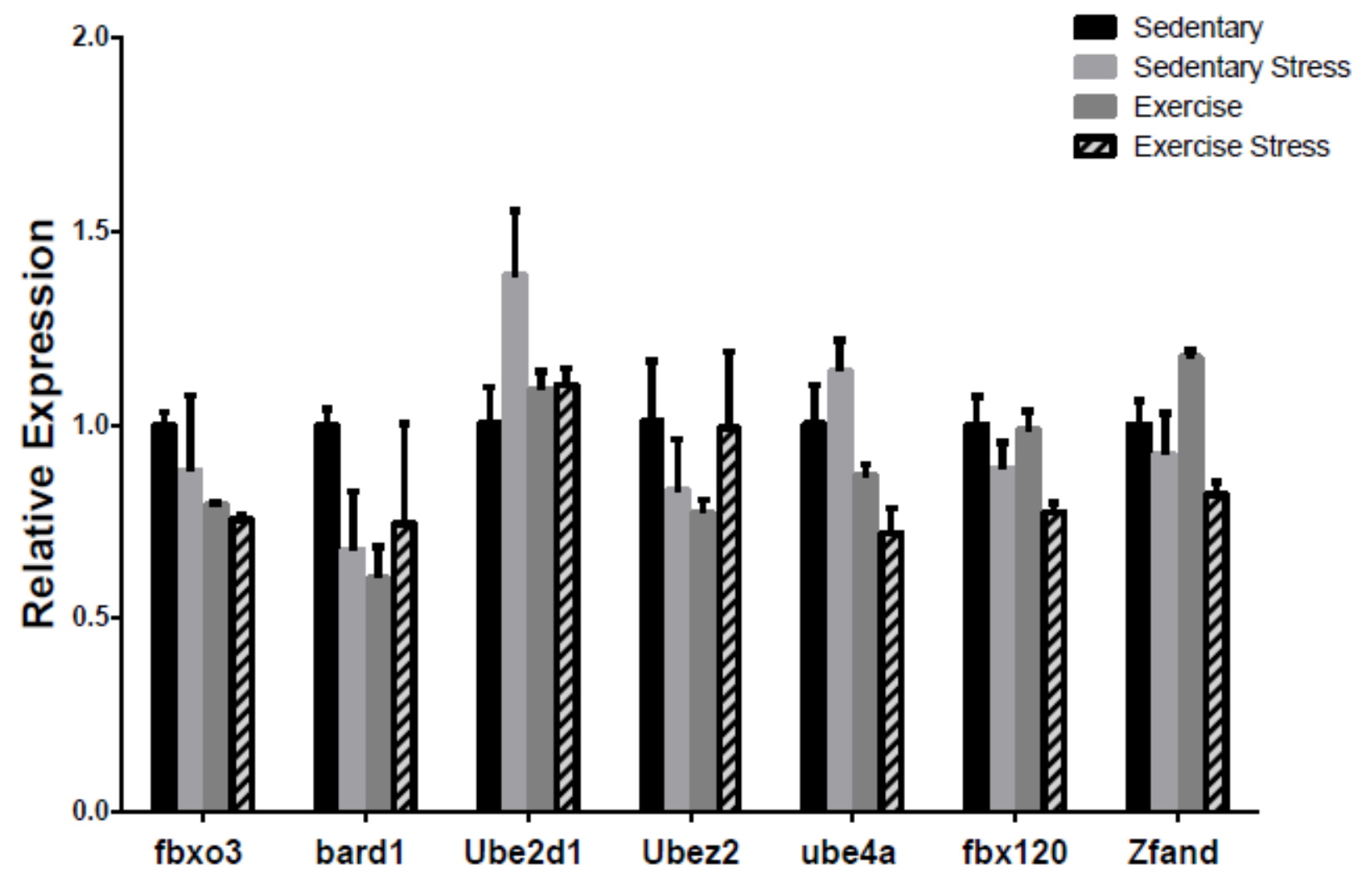

\begin{tabular}{|l|l|}
\hline GENE & FUNCTION \\
\hline Fbx03 & Fbox protein family, involved in phosphorylation dependent ubiquination \\
\hline Bard1 & Mediates E3 ubiquitin ligase activity \\
\hline Ube2d1 & Ubiquitin dependent protein catabolic process \\
\hline Ubez2 & E3 ubiquitin ligase \\
\hline Ube4a & Catalyzes ubiquitin chain assembly in conjunction with E1, E2, E3 \\
\hline Fbx120 & E3 ubiquitin ligase \\
\hline Zfand & Involved in protein degradation via the ubiquitin proteasome system. \\
\hline
\end{tabular}


Supplemental Figure 2

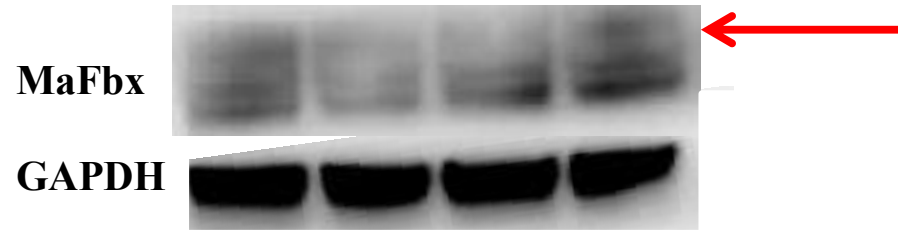


Supplemental Figure 3

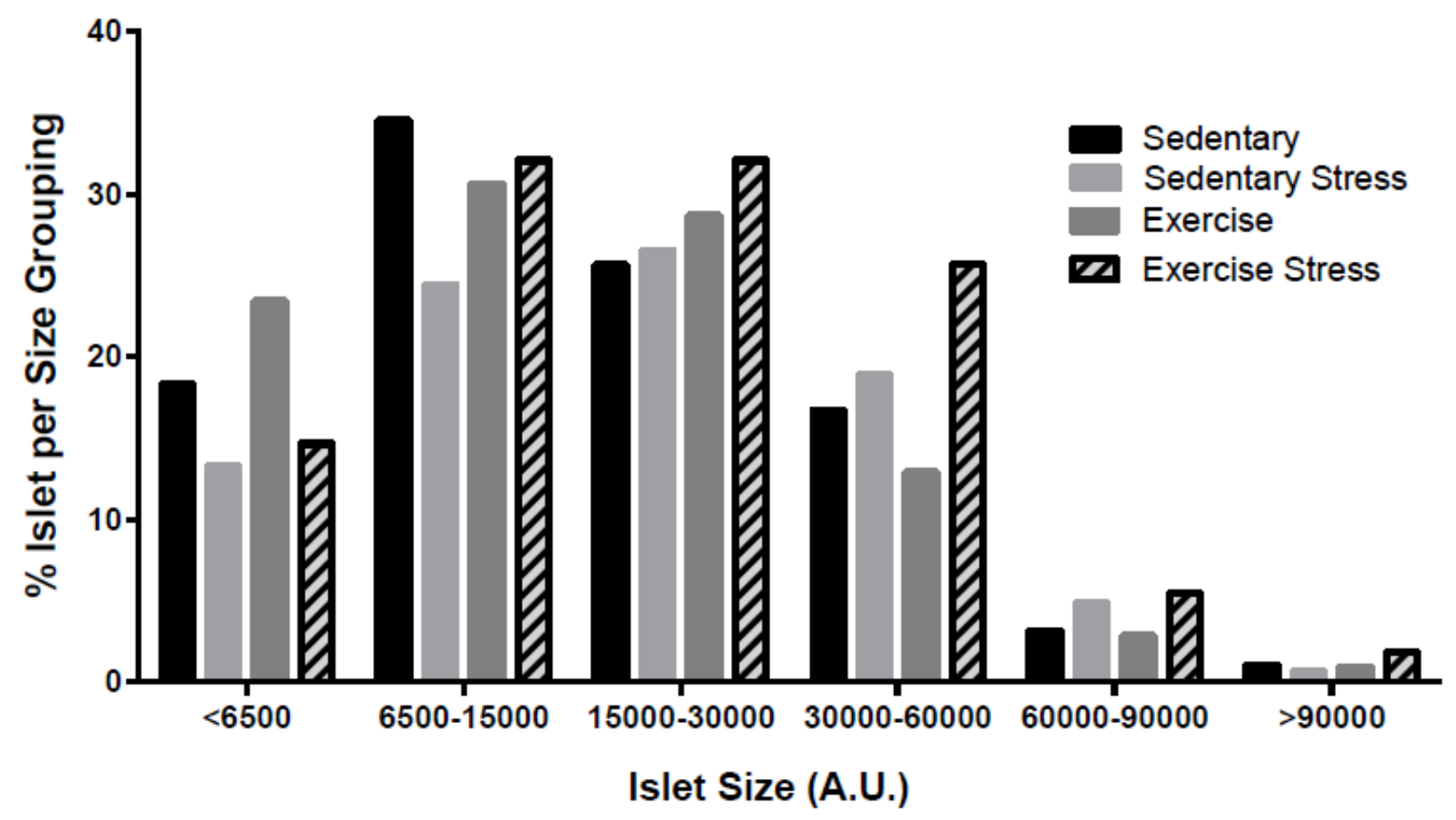

68 


\section{Appendix}

\section{Glucocorticoids}

GC released from the adrenal cortex, namely cortisol (in humans) or corticosterone (in rodents) are the end point of the HPA and are steroid derived hormones with wide ranging effects $^{102}$. Upon their release into the circulation GC's are influenced by corticosteroid binding globulin (CBG) which binds over $90 \%$ of circulating glucocorticoids. Circulating GCs are also influenced by 11 B hydroxysteroid dehydrogenase which exists in two forms (1 and 2) and interconverts GC's into their active or inactive forms respectively ${ }^{59}$. GC's are one of the most commonly used anti-inflammatory and immunodulatory agents ${ }^{103}$. They are mainly known for their anti-inflammatory effects, but are also widely used to treat immune disorders, allergies, and allograft rejection $^{104}$. The anti-inflammatory and metabolic effects of glucocorticoids are mediated through their binding to their specific receptor which remains in an inactive form and resides within the cytoplasm of target cells ${ }^{105}$. The inactive GR is stabilized and forms large heterotrocomplexes with heat shock protein 90 (hsp90) and other heat shock proteins ${ }^{106}$. GC's binding to its receptor causes activation and results in a change in the GR conformation and hyperphosphorylation ${ }^{107}$. Activated receptor translocates to the nucleus, binds to DNA, and alters transcriptional target genes ${ }^{107}{ }^{104}$. The binding to the glucocorticoid response element (GRE) results in increased production of anti-inflammatory proteins including lipocortin-1, interleukin-10, and interleukin- $1^{104}$. In addition, the GRE binding has the ability to interfere with the DNA binding activity of NF-KB which is a major pro-inflammatory transcription factor ${ }^{107}$.

GCs have many essential functions throughout the body and without them an organism cannot survive. As an organism is faced with stressful stimuli (starvation, pain, trauma, stress, heat/cold) GCs are released from the HPA axis and serve to reduce the harmful results of these stressful stimuli ${ }^{107}$. They do this through alterations in metabolism, immune function and 
behavior. It has been hypothesized by Munck et al. that this occurs in order to suppress our natural defense mechanisms rather than to enhance them. They propose that the purpose of GCs is to not respond to the stress itself but to lower normal defense mechanisms that are turned on during stress and in doing so elicit protection from their harmful effects. ${ }^{108}$. When homeostasis does become threatened due to stress or hypoglycemia, the primary metabolic action of GC is stimulation of hepatic gluconeogenesis ${ }^{108}$ causing increased release of glucose into circulation. Further metabolic alterations occur as GCs decrease the uptake and utilization of glucose at peripheral tissues. Hornbrook et al. also found that GCs influence insulin signaling and cause decreases in the levels of IRS-1 which results in decreased glucose uptake. This results in a rapid rise in blood glucose and glucose availability to exercising muscles.

GCs also influence immune and inflammation pathways. As discussed previously, GCs cause the increased transcription of genes that would inhibit the synthesis, release, or efficacy of cytokines that promote immune or inflammatory reactions ${ }^{108}$. The inflammatory mediators are also inhibited by GCs such as histamine, bradykinin, eicosanoids, nitric oxide, elastase and plasminogen activator ${ }^{109110,111}$. Lastly GCs can elicit their response neurobiologically and through changes in behavior. GCs inhibition of glucose transport and utilization also occurs in the brain as it does in peripheral tissues ${ }^{112,113}$. In addition, GCs cause behavioral changes related to food intake. Cohn et al found that adrenalectomy rats had decreased feeding and food seeking behavior but this was reversed with GC administration. Interestingly and in further support of this, appetite peaks usually coincide with circadian GC cycle peaks ${ }^{114}$.Evidence is increasing that chronic stress and chronic activation of GCs become detrimental to the organism, possibly leading to the onset of inflammatory/autoimmune disease, psychiatric disorders and metabolic disorders such as metabolic syndrome and diabetes ${ }^{59}$. 